\title{
Influência da hidrociclonagem e da secagem por spray dryer nas propriedades reológicas de argilas bentoníticas
}

\section{(Influence of the hydrocycloning and drying by spray dryer on bentonite clays rheological properties)}

\author{
V. C. Marques ${ }^{1}$, H. C. Silva ${ }^{1}$, A. M. T. Rodrigues ${ }^{1}$, J. de M. Cartaxo', R. R. Menezes ${ }^{2}$, H. S. Ferreira ${ }^{1}$ \\ ${ }^{I}$ Departamento de Engenharia de Materiais, Centro de Tecnologia, Universidade Federal da Paraiba, \\ Campus I, J. Pessoa, PB 58051-900 \\ ${ }^{2}$ Unidade Acadêmica de Engenharia de Materiais, Centro de Ciência e Tecnologia Campina Grande, Campus I, \\ Universidade Federal de Campina Grande, PB 58109-970 \\ veronicacavalcante87@hotmail.com,hevairsilva@gmail.com,aymtrodrigues@gmail.com, \\ julianamelo25@gmail.com,romualdomenezes@gmail.com,hebersivini@gmail.com
}

\begin{abstract}
Resumo
A exploração desordenada ao longo dos anos das argilas bentoníticas do município de Boa Vista, PB, resultou no esgotamento das variedades nobres. Assim, o que existe atualmente são bentonitas com elevado percentual de minerais acessórios, elementos contaminantes a exemplo do quartzo, os quais influem negativamente nas propriedades reológicas das dispersões. O presente trabalho propõe concentrar dispersões dessas argilas pouco nobres pela operação de hidrociclonagem e posterior secagem por spray dryer, visando à obtenção de amostras com valores de reologia de acordo com norma EP-1EP-00011-A da Petrobrás. Assim, preparouse dispersões de três composições com as argilas Bofe, Chocolate, Verde-Lodo, Chocobofe e Sortida previamente selecionadas por planejamento experimental com concentrações de $4 \%$ em massa de argila para serem concentradas por hidrociclonagem. Os concentrados foram secos por spray dryer em duas condições de secagem. Os resultados evidenciaram a eficiência das operações de hidrociclonagem e secagem por spray dryer das misturas com notável melhoria nas propriedades reológicas.

Palavras-chave: bentonita, misturas, hidrociclonagem, spray dryer.
\end{abstract}

Abstract

The uncontrolled exploitation over the years of bentonite clays in Boa Vista, PB, Brazil, resulted in the exhaustion of noble varieties. So, what currently exists are bentonites with a high percentage of accessory minerals, contaminants such as the quartz, which have a negative influence on the rheological properties of the dispersions. This paper proposes concentrate dispersions of these little noble clays by hydrocycloning operation and further drying by spray dryer, in order to obtain samples with rheology values of according to standard EP-1EP-00011-A of Petrobras. Thus, dispersions prepared of three compositions with the clays Bofe, Chocolate, VerdeLodo, Chocobofe and Sortida previously selected by experimental design with concentrations of 4 wt. \% of clay to be concentrated by hydrocycloning. The concentrates were dried by spray dryer in two drying conditions. The results showed the efficiency of hydrocycloning operations and drying by spray dryer of the mixtures with remarkable improvement in the rheological properties.

Keywords: bentonite, mixtures, hydrocycloning, spray dryer.

\section{INTRODUÇÃO}

As argilas esmectíticas são materiais constituídos por um ou mais argilominerais esmectíticos e alguns minerais acessórios (principalmente quartzo, cristobalita, micas e feldspatos). Os argilominerais são trifórmicos, di- ou trioctaédricos, podendo apresentar substituição isomórfica do $\mathrm{Si}^{4+}$ por $\mathrm{Al}^{3+}$ nas posições tetraédricas e nas posições octaédricas o cátion pode ser $\mathrm{o} \mathrm{Al}^{3+}, \mathrm{Mg}^{2+}, \mathrm{Fe}^{2+}$, entre outros [1]. Contém ainda certo teor de elementos alcalinos e alcalino-terrosos [2]. Sendo utilizada para uma série de aplicações industriais, é usada na pelotização de minérios de ferro e como aglomerante de areias de moldagem usadas em fundição na indústria metalúrgica. $\mathrm{Na}$ indústria de borracha atua como carga inorgânica, na de papel, como cobertura e para descoloração de papel reciclado, na de alimentos, no descoramento de óleos vegetais, minerais e animais [2-4]. Já na indústria do petróleo funciona como viscosificante quando adicionada a fluidos de perfuração de poços [5].

Muitas das variedades das argilas de Boa Vista, PB, encontram-se esgotadas ou começando a rarear [6]. No entanto, as variedades comercializadas atualmente apresentam um elevado grau de contaminação por minerais acessórios, comprometendo suas aplicações tecnológicas [7], uma vez que prejudica suas propriedades reológicas, as quais são sensíveis à presença de contaminantes, como partículas de quartzo, cristobalita, micas e feldspatos [1]. Assim, propõe-se o uso de um hidrociclone para a 
concentração de bentonitas em escala industrial $[8,9]$.

Os hidrociclones constituem uma classe importante de equipamentos destinados à separação de suspensões sólidolíquido ou líquido-líquido. O princípio de separação é a sedimentação centrífuga, em que as partículas em suspensão são submetidas a um campo centrífugo que provoca sua separação do meio fluido [10,11]. Assim, por meio do campo centrífugo e devido à diferença de tamanho e densidade das partículas, têm-se as partículas menores e menos densas no overflow e as maiores e mais densas no underflow. Nos casos em que o material hidrociclonado precisa voltar à forma de pó, faz-se necessária a etapa de secagem, a qual é uma operação unitária de retirada de água de um produto por evaporação, mediante aplicação de calor sob condições controladas [12].

O spray dryer ou secador por nebulização, aspersão ou atomização, como também é conhecido, promove a secagem rápida de uma carga bombeável (solução, suspensão fina, geles, emulsões, etc.), obtendo um produto seco e pulverulento ou na forma de pequenos aglomerados, com taxas variando desde unidades do porte piloto até unidades industriais com produção de $25 \mathrm{t} / \mathrm{h}$ de sólidos [13, 14].

Este trabalho teve por objetivo concentrar o argilomineral de misturas de argilas bentoníticas pouco nobres por meio do processo de hidrociclonagem, e posterior secagem por spray dryer, visando otimizar as propriedades reológicas das dispersões de modo que atendam as exigências da norma EP1EP-00011-A da Petrobrás [5]. A eficiência das operações de beneficiamento das misturas foi verificada por análise granulométrica e difração de raios X.

\section{MATERIAIS E MÉTODOS}

Materiais: foram utilizadas cinco amostras de bentonitas policatiônicas provenientes da Mina Juá II, Boa Vista, PB, denominadas Bofe, Chocolate, Verde-Lodo, Chocobofe e Sortida e o defloculante carbonato de sódio $\left(\mathrm{Na}_{2} \mathrm{CO}_{3}\right)$. Todos os materiais foram cedidos pela Bentonit União Nordeste.

Métodos: as amostras foram secas em estufa a $60{ }^{\circ} \mathrm{C}$ por 3 dias. Em seguida foram trituradas em britador de mandíbulas e moídas em moinho de discos da marca Marconi MA700. As amostras para a operação de hidrociclonagem foram peneiradas em peneira ABNT $16(1,18 \mathrm{~mm})$.

Análise granulométrica por difração a laser: as dispersões foram agitadas em agitador Marconi MA147 a velocidade de $20000 \mathrm{rpm}$ por $5 \mathrm{~min}$. Em seguida, foram colocadas em um equipamento Cilas 1064, em modo úmido até atingir a concentração de 180 unidades de difração/área de incidência.

Análise química por fluorescência de raios $X$ : foi realizada em modo quali-quanti em espectrômetro FRX 1800 Shimadzu, no qual os raios X são gerados em tubo com alvo de Rh.

Difração de raios $X$ : as análises por difração de raios $\mathrm{X}$ das amostras de argilas bentoníticas foram realizadas em difratômetro XRD 6000 Shimadzu. A radiação utilizada foi Cuk $\alpha, 2 \%$ min e passo $0,02^{\circ}$.

Análise termogravimétrica e térmica diferencial: as curvas térmicas foram obtidas simultaneamente por meio do
TA $60 \mathrm{H}$ Shimadzu. A varredura foi na faixa da temperatura ambiente até $1000{ }^{\circ} \mathrm{C}$, sendo a taxa de aquecimento $12,5^{\circ} \mathrm{C} / \mathrm{min}$ e o padrão o óxido de alumínio $\left(\alpha-\mathrm{Al}_{2} \mathrm{O}_{3}\right)$.

Operação de hidrociclonagem: para a operação de hidrociclonagem foram utlizadas as misturas obtidas na primeira etapa deste trabalho [15] que apresentaram os melhores resultados para as propriedades reológicas sem a etapa de concentração de argilominerais, as quais teriam mais chances de se adequarem as exigências normativas após a hidrociclonagem. As misturas hidrociclonadas estão na Tabela I.

Tabela I - Composição das misturas hidrociclonadas. [Table I - Composition of mixtures hydrocycloning.]

\begin{tabular}{|c|c|c|c|}
\hline Mistura & $\begin{array}{c}\text { Aditivação } \\
\text { (meq de } \mathrm{Na}_{2} \mathrm{CO}_{3} / \\
100 \text { g de argila) }\end{array}$ & Argilas & $\begin{array}{c}\text { Proporções } \\
(\%)\end{array}$ \\
\hline \multirow{4}{*}{ M1 } & \multirow{4}{*}{125} & Bofe & 8,40 \\
\hline & & Chocolate & 22,50 \\
\hline & & Verde-Lodo & 69,10 \\
\hline & & Bofe & 30,30 \\
\hline \multirow[t]{3}{*}{ M2 } & \multirow[t]{2}{*}{125} & Verde-Lodo & 51,70 \\
\hline & & Chocobofe & 18,00 \\
\hline & \multirow{3}{*}{125} & Bofe & 36,00 \\
\hline \multirow[t]{2}{*}{ M3 } & & Verde-Lodo & 50,30 \\
\hline & & Sortida & 13,70 \\
\hline
\end{tabular}

O hidrociclone utilizado é o RWK 42L Netzsch O corpo do hidrociclone apresenta diâmetro externo de $35 \mathrm{~mm}$ e interno de $20 \mathrm{~mm}$, sendo composto de três diâmetros de ápex e dois de vórtex com as dimensões indicadas na Tabela II.

Tabela II - Dimensões de ápex e vórtex do hidrociclone. [Table II - Dimensions of the apex and vortex of the hydrocyclone.]

\begin{tabular}{cccccc}
\hline Saídas & \multicolumn{3}{c}{ Vórtex } & \multicolumn{3}{c}{ Ápex } \\
\hline Nomenclatura & A & B & 1 & 2 & 3 \\
Diâmetro interno $(\mathrm{mm})$ & 5 & 6 & 4 & 3 & 5 \\
\hline
\end{tabular}

Assim, pode assumir qualquer uma das seis possíveis combinações. No entanto, no presente trabalho as hidrociclonagens foram realizadas apenas com as configurações A1 e A3 [9], uma vez que se apresentaram mais eficientes em termos de separação por tamanho de partículas e análise mineralógica, critérios de eficiência utilizados no presente trabalho para a operação de hidrociclonagem. As dispersões para a operação de hidrociclonagem foram preparadas a partir de $4 \%$ em massa de argila seca e a água destilada foi previamente aquecida a $80^{\circ} \mathrm{C}$ [16] para facilitar a troca catiônica. As dispersões permaneceram em agitação a $2000 \mathrm{rpm}$ por $24 \mathrm{~h}$ em dispersor de $5 \mathrm{~kW}$. Ao final da agitação, passou-se para a hidrociclonagem, a qual ocorreu 
em apenas um ciclo e a uma pressão de 3 bar. Após a operação de hidrociclonagem, os concentrados de argilominerais foram secos por spray dryer de forma a atender a normatização que exige que a comercialização destes materiais seja feita apenas na forma de pó.

Secagem por spraydryer: os concentrados de argilominerais obtidos pela operação de hidrociclonagem foram secos por spray dryer LM SD 5.0 Labmaq do Brasil, submetidos a duas condições de secagem, na primeira com vazão de $35 \mathrm{~L} / \mathrm{min}$ e na segunda com vazão de $50 \mathrm{~L} / \mathrm{min}$ de ar comprimido. Em ambos os casos a temperatura do ar na saída da câmara de secagem foi controlada em $60{ }^{\circ} \mathrm{C}$ e a vazão do soprador de ar controlada em $2,9 \mathrm{~m}^{3} / \mathrm{min}$. No spray dryer o sistema de atomização é composto de um bico duplo fluido, sendo a alimentação das dispersões à câmara de secagem realizada na parte inferior através de uma bomba peristáltica, na qual controlou-se a vazão em $5 \mathrm{~L} / \mathrm{h}$. A suspensão pulverizada e o ar de secagem têm o mesmo sentido de corrente dentro do equipamento. Posteriormente, verificou-se o comportamento reológico de dispersões preparadas a partir do material atomizado obtido para verificação do cumprimento à norma EP-1EP-00011-A da Petrobras [5].

Preparo das dispersões: para preparo das dispersões utilizou-se um agitador Marconi MA147 e seguiu-se o padrão EP-1EP-00011-A da Petrobras [5]. A água destilada foi previamente aquecida a $80{ }^{\circ} \mathrm{C}$ [16] para facilitar a ativação sódica feita pelo defloculante, que promove defloculação da argila e consequente melhoria das propriedades reológicas. Após os primeiros $5 \mathrm{~min}$ de agitação, as dispersões foram aditivadas com carbonato de sódio $\left(\mathrm{Na}_{2} \mathrm{CO}_{3}\right)$ nas proporções indicadas na Tabela $\mathrm{I}$, sendo a concentração de $\mathrm{Na}_{2} \mathrm{CO}_{3} 0,2 \mathrm{~g} / \mathrm{mL}$.

Estudo reológico: Foi realizado segundo o padrão EP1EP-00011-A da Petrobras [5], sendo determinadas as viscosidades aparente (VA) e plástica (VP) em viscosímetro Fann 35A e o volume de filtrado (VF) em filtro Fann HPLT. A mesma norma especifica requisitos para os valores dessas propriedades, em que os valores de VA e VP para fluidos hidroargilosos devem ser de no mínimo $15 \mathrm{cP}(0,015$ Pa.s $)$ e
4 cP $(0,004$ Pa.s), respectivamente. Já o valor para o VF deve ser de no máximo $18 \mathrm{~mL}$.

Codificação das amostras: nos resultados de AG e DRX das amostras hidrociclonadas, as mesmas estão codificadas segundo o formato: mistura, a qual tem a composição indicada na Tabela I, configuração do hidrociclone, indicada na Tabela II, e se a amostra trata-se da dispersão original (D), do concentrado de argilominerais (P), overflow, ou do rejeito (R), underflow. Como exemplo tem-se, M1_A1_D: significando que essa amostra é a dispersão original $(\bar{D})$ da mistura 1 (M1), a qual passou pela configuração A1 do hidrociclone para originar as amostras M1_A1_P (a amostra concentrada) e M1_A1_R (a amostra rejeito). As dispersões originais (D) que foram caracterizadas por AG e DRX não passaram pelo processo de hidrociclonagem. No entanto, na codificação dessas amostras aparece a configuração do hidrociclone como forma de identificar dispersões originais que passaram por diferentes configurações do hidrociclone, originando diferentes concentrados de argilominerais e rejeitos. Já nos resultados de AG dos concentrados de argilominerais obtidos por hidrociclonagem e secos por spray dryer, as amostras estão codificadas segundo o formato: mistura, a qual tem a composição indicada na Tabela I, configuração do hidrociclone, indicada na Tabela II, que a amostra trata-se do concentrado de argilominerais (P) e se este foi seco por spray dryer a $35 \mathrm{~L} / \mathrm{min}(35)$ de ar comprimido ou a $50 \mathrm{~L} / \mathrm{min}$ (50) de ar comprimido. Como exemplo tem, M1_A1_P_35: a amostra é o concentrado de argilominerais (P) da mistura 1 (M1), a qual passou pela configuração A1 do hidrociclone e foi seco por spray dryer a $35 \mathrm{~L} / \mathrm{min}$ (35) de ar comprimido.

\section{RESULTADOS E DISCUSSÃO}

\section{Análise granulométrica por difração a laser}

Nas Figs. 1a e 1b são apresentados os resultados das análises granulométricas por difração a laser de cada uma das argilas. É possível observar uma distribuição de partículas multimodal para as argilas Bofe e Chocobofe.

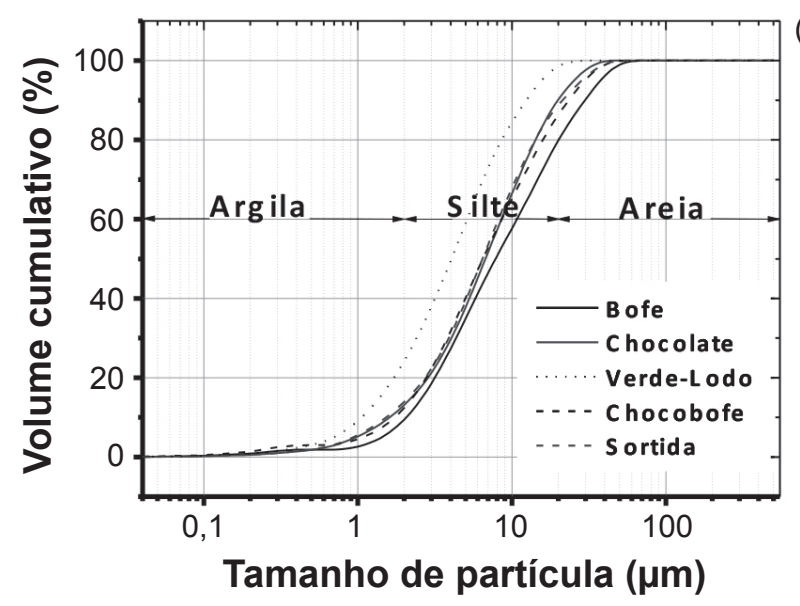

(a)

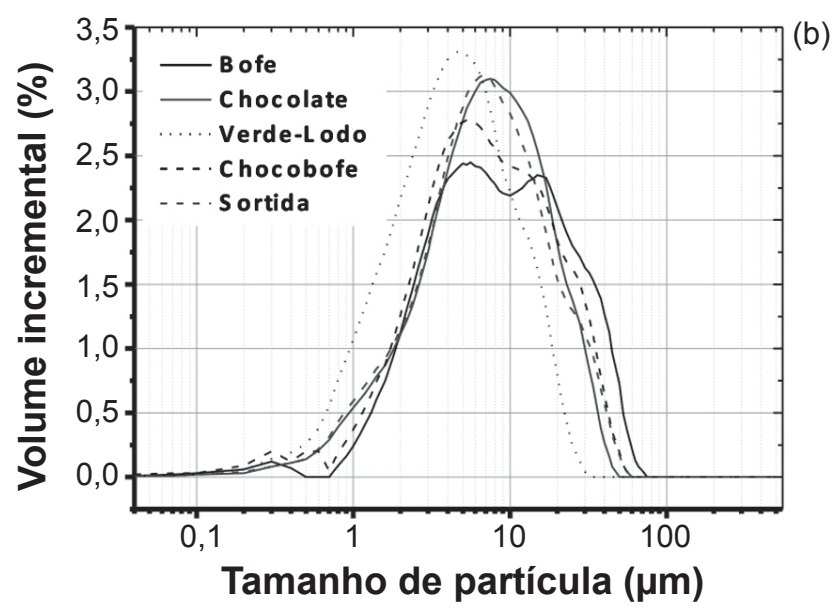

Figura 1: Curvas de granulometria das argilas. (a) volume acumulado passante e (b) distribuição do tamanho de partículas. [Figure 1: Particle size of clays. (a) cumulative volume passing and (b) particle size distribution.] 
As demais argilas apresentaram distribuição monomodal. Os diâmetros médios $\left(\mathrm{D}_{\mathrm{m}}\right)$ estão entre $5,50 \mu \mathrm{m}$ para a argila Verde-Lodo e 12,24 $\mu \mathrm{m}$ para a argila Bofe. Já os $\mathrm{D}_{50}$ estão entre $4,05 \mu \mathrm{m}$ para a argila Verde-Lodo e 7,82 $\mu \mathrm{m}$ para a argila Bofe. Ainda verifica-se que a porcentagem da massa acumulada com diâmetro médio equivalente abaixo de $2 \mu \mathrm{m}$, que corresponde à fração argila está entre $9,43 \%$ para a argila Bofe e $24,20 \%$ para a argila Verde-Lodo.

A presença de frações com tamanhos superiores a $2 \mu \mathrm{m}$, referentes às frações silte e areia, pode ser aglomerados de argila presentes mesmo após a dispersão da amostra $[1,9]$.

\section{Composição química por fluorescência de raios X}

Na Tabela III, onde são apresentadas as composições químicas das amostras de argilas bentoníticas em estudo, observa-se elevado conteúdo de $\mathrm{SiO}_{2}$, devido a silicatos, como os argilominerais, e a sílica livre, proveniente principalmente de quartzo. $\mathrm{O}$ teor de $\mathrm{Al}_{2} \mathrm{O}_{3}$ variou de $12,45 \%$ para a argila Bofe a 19,20\% para a argila Chocolate. O alumínio presente está em sua maior parte combinado formando os argilominerais [2]. Observam-se também baixos teores de $\mathrm{CaO}$ e $\mathrm{MgO}$, os quais podem ser na forma de cátion trocável, principalmente se não existirem minerais como calcita, dolomita e gipsita, dos quais esses óxidos poderiam ser originados [2], e a presença em pequenas frações de $\mathrm{Na}_{2} \mathrm{O}$ e $\mathrm{K}_{2} \mathrm{O}$ em todas as amostras, podendo ser atribuída aos feldspatos e cátions trocáveis [2]. $\mathrm{O}$ teor de $\mathrm{Fe}_{2} \mathrm{O}_{3}$ variou de 4,29\% para a argila Bofe à 8,96\% para a Chocobofe. Estes teores são provenientes do reticulado cristalino da ilita e dos argilominerais do grupo da esmectita, em que o ferro faz parte do reticulado cristalino [2]. A perda ao fogo representa a perda de água intercalada, a perda de água de hidroxilas dos argilominerais, perda de hidróxidos e matéria orgânica [2]. No presente trabalho, a argila Chocolate apresentou a maior PF, $11,58 \%$.

\section{Difração de raios $X$}

Nas figuras a seguir são apresentados os difratogramas de cada uma das argilas. A identificação foi feita pelo X'Pert HighScore, 2001, por meio de comparações com padrões contidos no programa computacional PDF 02 (ICDD, 2003). A argila Bofe, Fig. 2a, além de montmorilonita com o pico mais intenso na distância interplanar de $14,35 \AA$ ( $2 \theta$ $=6,16$ ), contém os minerais cristobalita, caulinita e quartzo, o principal contaminante, o qual apresenta a distância interplanar de $3,33 \AA(2 \theta=26,76)$. Também está presente o oxalato de cálcio hidratado, whewellite, o qual tem origem da degradação biológica em depósitos de argilas. Já a argila Chocolate, Fig. 2b, apresenta o argilomineral montmorilonita, estando o pico mais intenso na distância de $14,44 \AA(2 \theta=6,12)$. Observa-se também a presença de minerais contaminantes como hematita, caulinita, ortoclásio e quartzo.

Por meio do difratograma da argila Verde-Lodo, Fig. 3a, observam-se picos relativos ao argilomineral montmorilonita nas distâncias de $14,71 \AA(2 \theta=6,00), 4,49 \AA(2 \theta=19,74)$, $3,57 \AA(2 \theta=24,95), 3,05 \AA(2 \theta=29,32), 2,57 \AA(2 \theta=34,95)$ e $1,68 \AA(2 \theta=54,58)$. Ainda, observam-se picos a 4,26 $\AA(2 \theta=20,84)$ e $3,35 \AA(2 \theta=26,60)$, característicos dos mais intensos de quartzo. Também estão presentes nesta argila os contaminantes ilita, caulinita e ortoclásio. Já na argila Chocobofe, Fig. 3 (b), além do principal pico do argilomineral montmorilonita a $14,22 \AA(2 \theta=6,21)$, há um pico a $4,10 \AA(2 \theta=21,70)$ relativo à cristobalita e picos

Tabela III - Composição química das argilas bentoníticas.

[Table III - Chemical composition of bentonite clays.]

\begin{tabular}{cccccc}
\hline Compostos & Bofe & Chocolate & Verde-Lodo & Chocobofe & Sortida \\
\hline $\mathrm{SiO}_{2}(\%)$ & 71,23 & 55,61 & 55,82 & 62,72 & 63,57 \\
$\mathrm{Al}_{2} \mathrm{O}_{3}(\%)$ & 12,45 & 19,20 & 18,82 & 13,81 & 15,55 \\
$\mathrm{Fe}_{2} \mathrm{O}_{3}(\%)$ & 4,29 & 8,55 & 8,25 & 8,96 & 6,72 \\
$\mathrm{MgO}(\%)$ & 1,18 & 1,82 & 2,56 & 1,57 & 2,05 \\
$\mathrm{CaO}(\%)$ & 0,83 & 1,14 & 1,07 & 0,78 & 1,22 \\
$\mathrm{TiO}_{2}(\%)$ & 0,68 & 1,02 & 1,22 & 0,93 & 0,85 \\
$\mathrm{~K}_{2} \mathrm{O}(\%)$ & 0,25 & 0,41 & 1,25 & 0,50 & 0,28 \\
$\mathrm{SO}_{3}(\%)$ & 0,16 & 0,29 & 0,04 & 0,84 & 0,05 \\
$\mathrm{Na}_{2} \mathrm{O}(\%)$ & 0,11 & 0,16 & 0,37 & 0,37 & 0,24 \\
Outros Óxidos (\%) & 0,18 & 0,22 & 0,30 & 0,27 & 0,26 \\
$\mathrm{PF}^{(\%)}$ & 8,63 & 11,58 & 10,30 & 9,24 & 9,20 \\
\hline
\end{tabular}



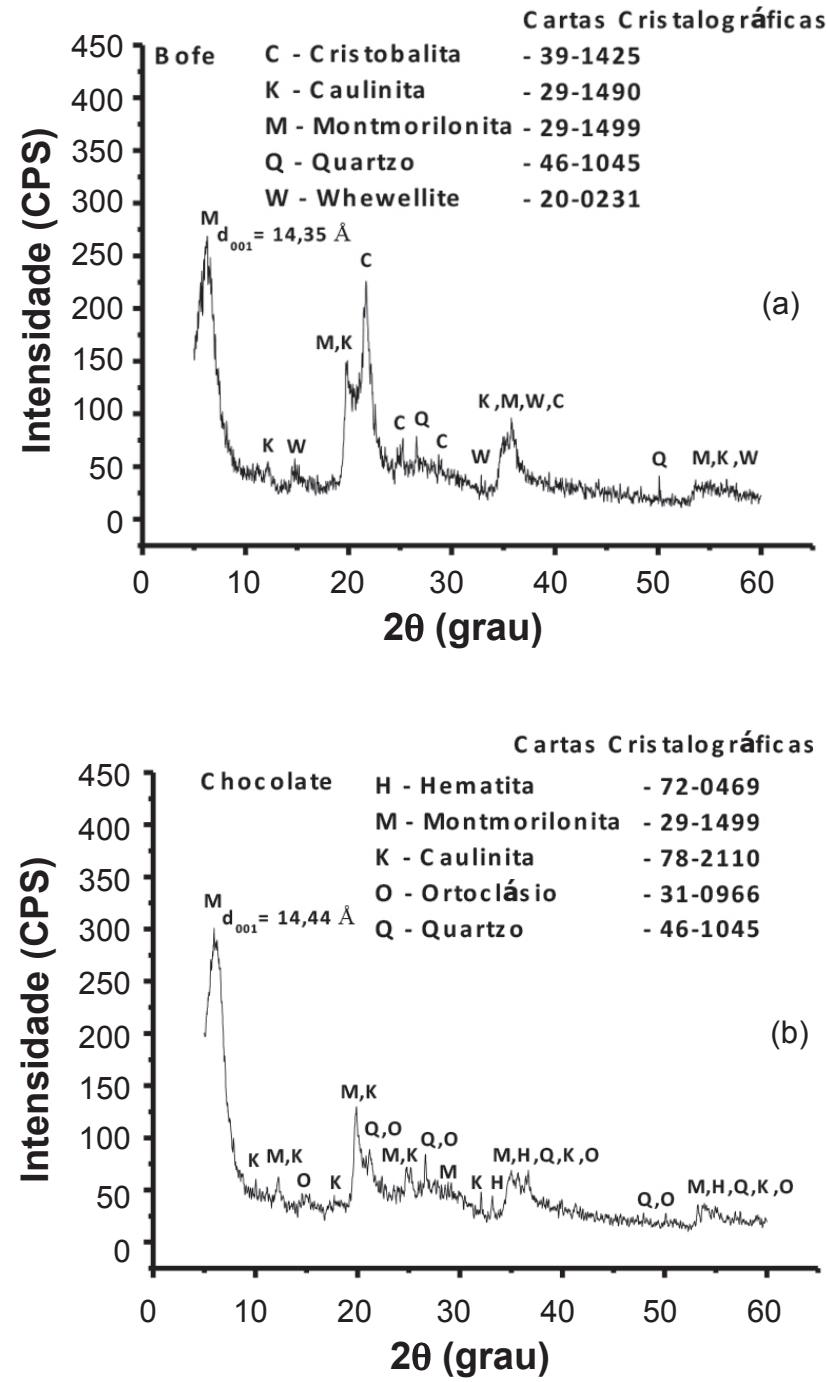

Figura 2: Difratogramas de raios $\mathrm{X}$ das argilas (a) Bofe e (b) Chocolate.

[Figure 2: X-ray diffraction patterns of the clays (a) Bofe and (b) Chocolate.]

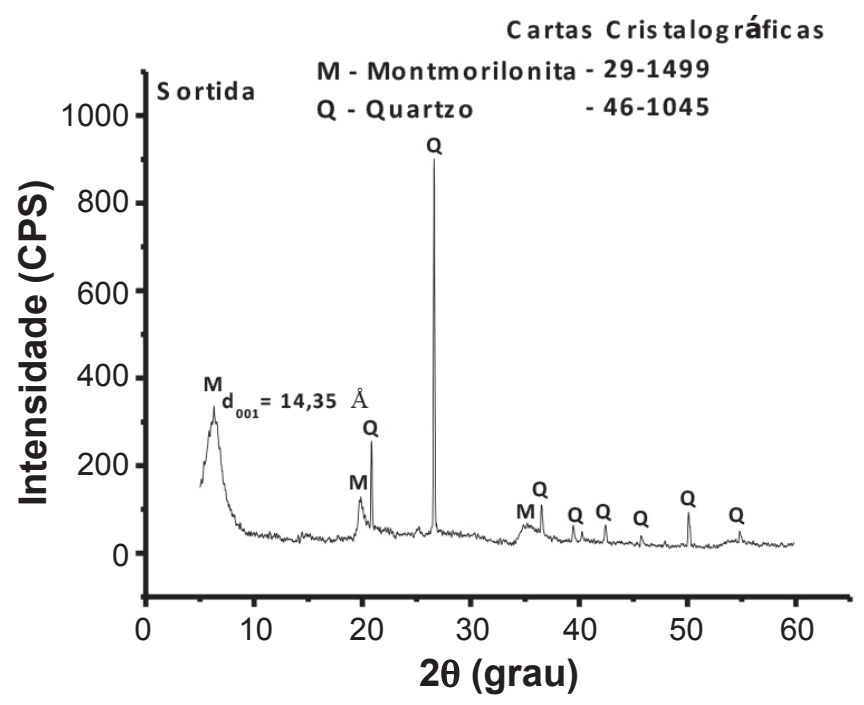

Figura 4: Difratograma de raios X da argila Sortida. [Figure 4: X-ray diffraction pattern of the Sortida clay.]
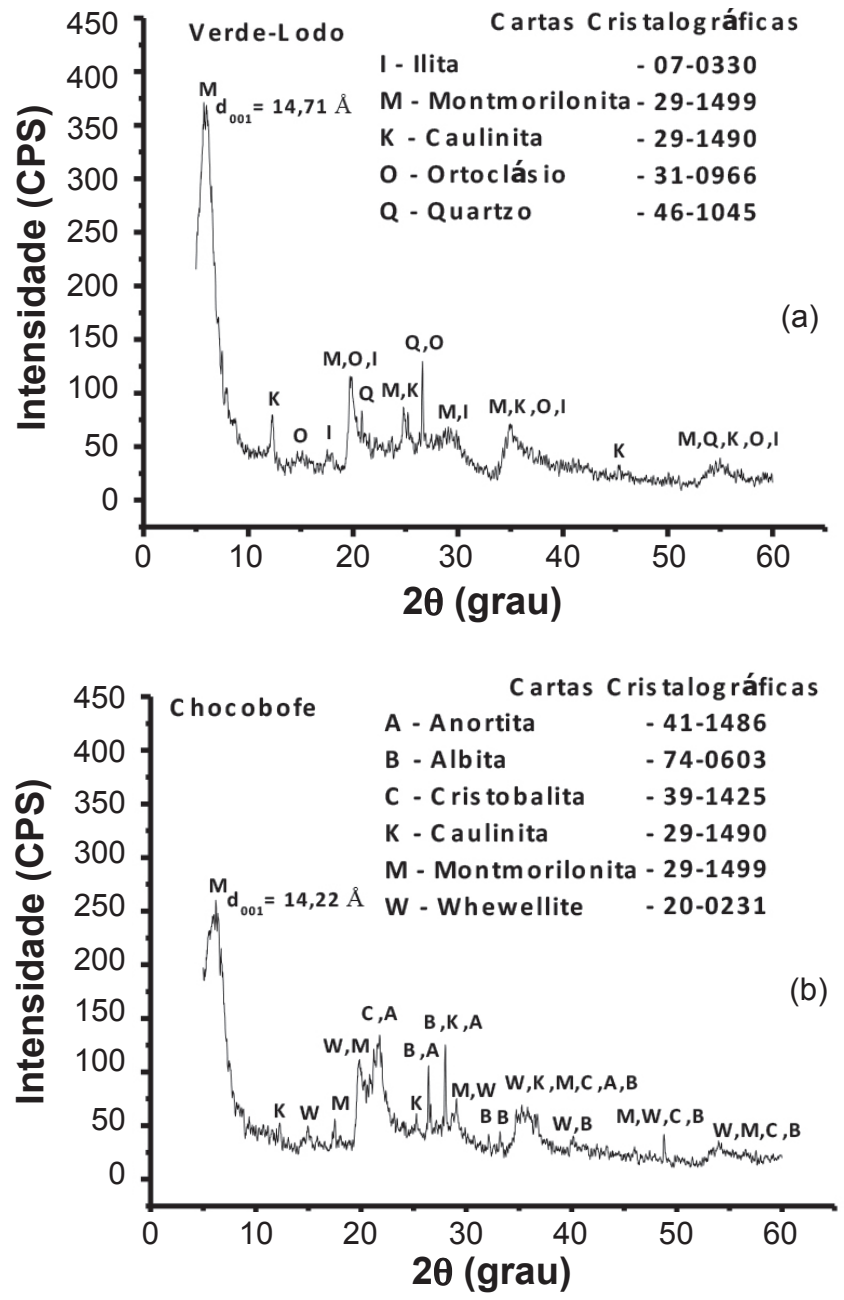

Figura 3: Difratogramas de raios $\mathrm{X}$ das argilas (a) Verde-Lodo e (b) Chocobofe.

[Figure 3: X-ray diffraction patterns of the clays (a) Verde-Lodo and (b) Chocobofe.]

a $4,10 \AA(2 \theta=21,70), 3,37 \AA(2 \theta=26,44)$ e $3,19 \AA$ $(2 \theta=28,00)$ referentes ao feldspato cálcico, anortita. Também estão presentes os minerais albita, caulinita e o oxalato de cálcio hidratado, whewellite.

No difratograma da Fig. 4 verifica-se que a argila Sortida é composta apenas por montmorilonita, com o principal pico a $14,35 \AA(2 \theta=6,16)$, e quartzo, com picos intensos a 4,26 $\AA(2 \theta=20,84)$ e $3,35 \AA(2 \theta=26,62)$.

Os difratogramas revelam que as argilas estudadas são compostas predominantemente por argilominerais do grupo da esmectita, mais precisamente pelo argilomineral montmorilonita, juntamente com minerais acessórios como quartzo, caulinita e feldspatos.

Análise termogravimétrica (TG) e análise térmica diferencial (ATD)

Nas Figs. 5a e 5b estão representadas as curvas de ATD e TG de cada uma das argilas, mostrando que as argilas têm comportamento térmico semelhante, apresentando picos endotérmicos por volta de $80{ }^{\circ} \mathrm{C}$, o qual se deve à perda 

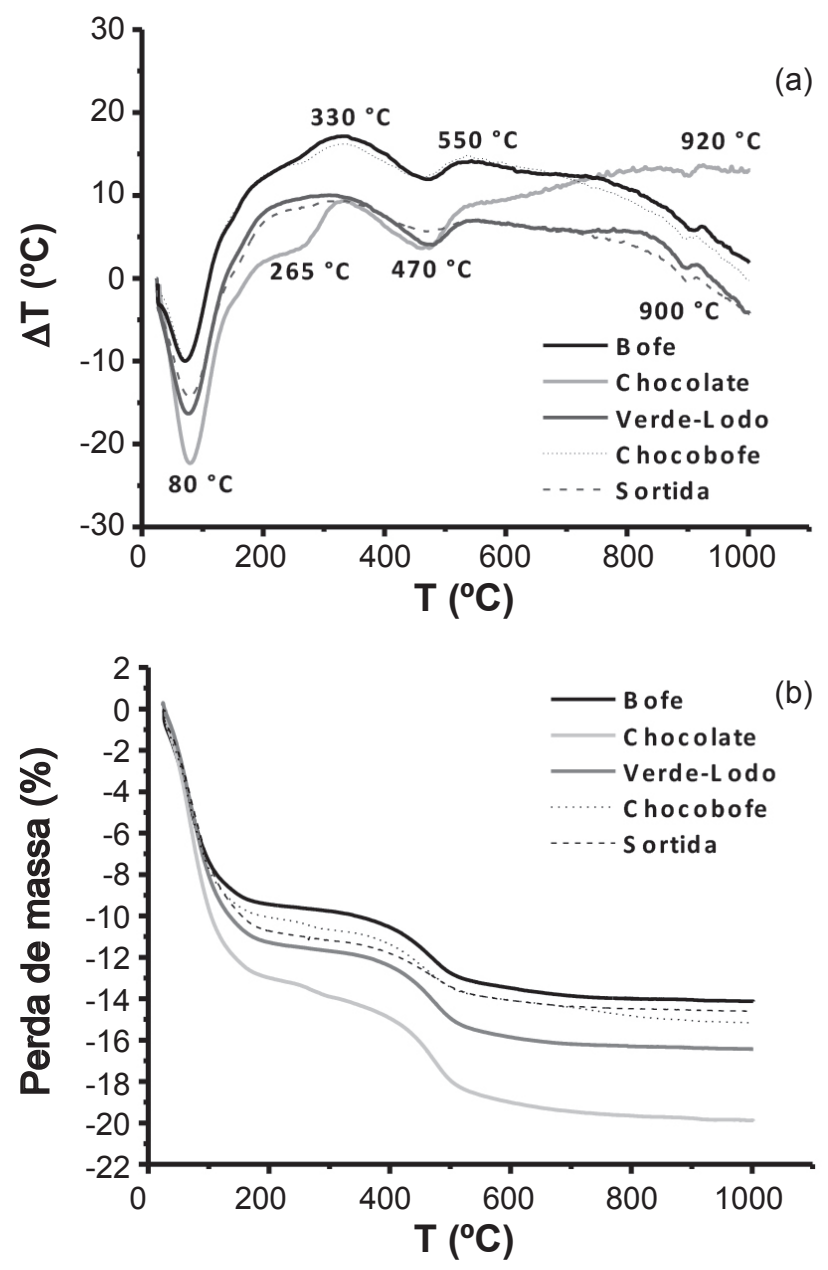

Figura 5: Curvas (a) ATD e (b) TG das argilas.

[Figure 5: DTA (a) and TG (b) curves of clays.]

de água. Os picos em $265{ }^{\circ} \mathrm{C}$ e $330{ }^{\circ} \mathrm{C}$ correspondem à perda de hidróxidos e matéria orgânica, respectivamente. Já o pico endotérmico em $470{ }^{\circ} \mathrm{C}$ é característico da perda de hidroxilas estruturais. O pico exotérmico em $550{ }^{\circ} \mathrm{C}$ corresponde à grafitização, sendo esta a formação de carbono grafite a partir da queima de compostos com carbono e matéria orgânica. Já o pico endotérmico em $900{ }^{\circ} \mathrm{C}$ é relativo à destruição do retículo cristalino do argilomineral e o pico exotérmico por volta de $920{ }^{\circ} \mathrm{C}$ corresponde à nucleação de mulita a partir da alumina, originada da destruição do retículo cristalino, e do quartzo livre presente na argila. Quanto às curvas TG, verifica-se que a perda total de massa foi de $14,08 \%, 19,89 \%, 16,60 \%$, $15,11 \%, 14,60 \%$ para as argilas Bofe, Chocolate, VerdeLodo, Chocobofe e Sortida, respectivamente. Essa perda de massa corresponde a dois eventos, no qual o primeiro deve-se a perda de água e o segundo de hidroxila. Os resultados de PF na análise química podem ser ratificados pelas perdas totais de massa na TG. Em ambas as análises a argila Chocolate apresenta as maiores perdas de massa. A diferença dos valores reportados pela PF e pela TG deve-se às particularidades de cada análise, em que na TG a análise da amostra tem início a temperatura ambiente. Já na PF, a amostra deve ser seca a $110^{\circ} \mathrm{C}$ antes da queima em mufla.
Análise granulométrica por difração a laser $(A G)$ das amostras hidrociclonadas

A seguir são apresentados os resultados de AG realizada nas misturas M1, M2 e M3 após a operação de hidrociclonagem nas configurações A1 e A3 do hidrociclone. Das Figs. 6a e 6b é possível inferir que todas as amostras apresentam curva de distribuição de partículas monomodal. Os diâmetros médio $\left(D_{m}\right)$ e $D_{50}$ são, respectivamente, $5,63 \mu \mathrm{m}$ e $4,27 \mu \mathrm{m}$ para M1_A1_D, 7,38 $\mu \mathrm{m}$ e 5,79 $\mu \mathrm{m}$ para M1_A1_R, 3,49 $\mu \mathrm{m}$ e 2,95 $\mu \mathrm{m}$ para M1_A1_P, $5,42 \mu \mathrm{m}$ e 4,10 $\mu \mathrm{m}$ para M1_A3_D, $7,05 \mu \mathrm{m}$ e $5,45 \mu \mathrm{m}$ para M1 A3 R, 3,56 $\mu \mathrm{m}$ e $3,00 \mu \mathrm{m}$ para M1_A3 P. Ainda é possível observar que a porcentagem da massa acumulada que apresenta diâmetro médio equivalente abaixo de $2 \mu \mathrm{m}$, que corresponde à fração argila, é de $24,40 \%$ para M1_A1_D, 17,05\% para M1_A1_R, 33,98\% para M1 A1_P, 25,93\% para M1_A3_D, 19,07\% para M1_A3_R e 33,48\% para M1_A3_P.

Das Figs. 7a e 7b é possível inferir que todas as amostras
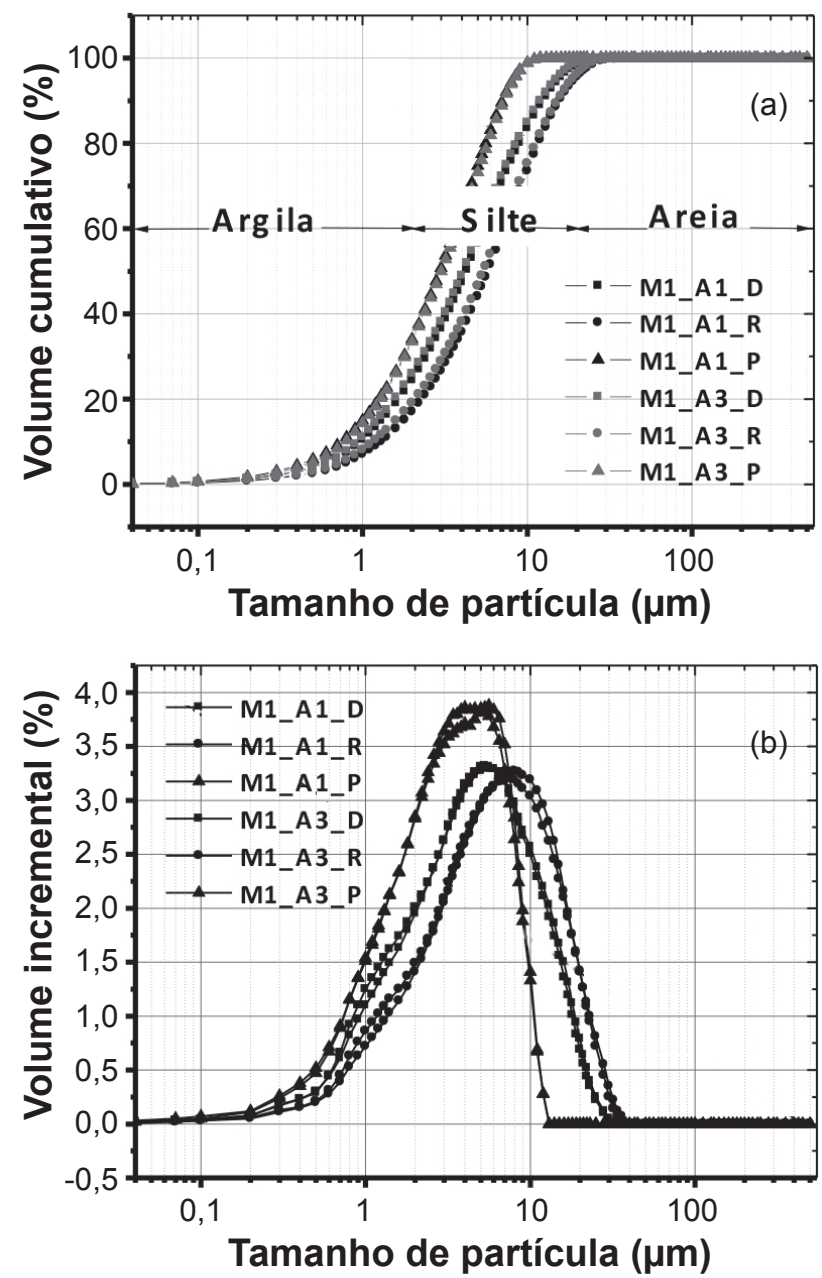

Figura 6: Curvas de granulometria da mistura M1 nas configurações A1 e A3 do hidrociclone. (a) volume acumulado passante e (b) distribuição do tamanho de partículas.

[Figure 6: Particle size of the mixture M1 in the configurations A1 and $A 3$ of the hydrocyclone. (a) cumulative volume passing and (b) particle size distribution.] 

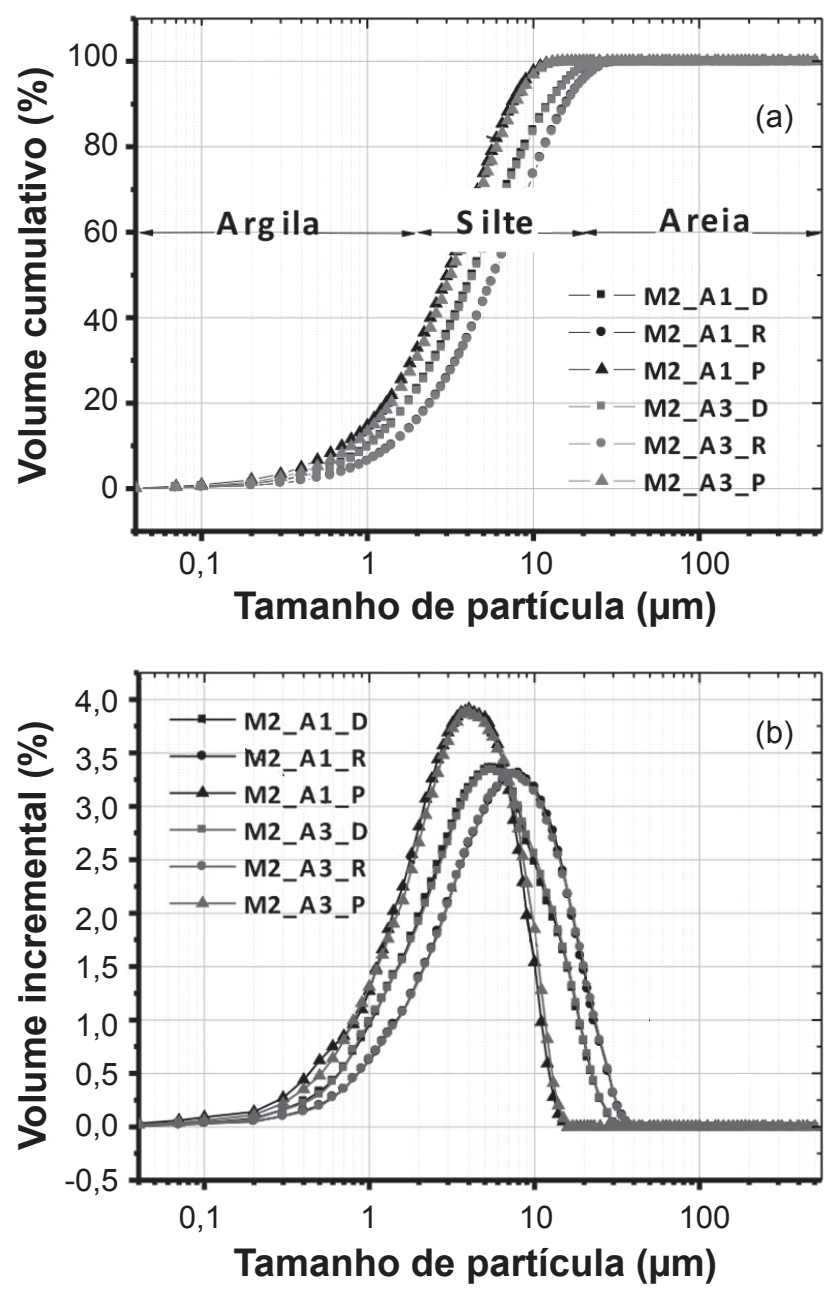

Figura 7: Curvas de granulometria da mistura M2 nas configurações A1 e A3 do hidrociclone. (a) volume acumulado passante e (b) distribuição do tamanho de partículas.

[Figure 7: Particle size of the mixture M2 in the configurations A1 and $A 3$ of the hydrocyclone. (a) cumulative volume passing and (b) particle size distribution.]

apresentam curva de distribuição de partículas monomodal. As amostras apresentam diâmetros médio $\left(\mathrm{D}_{\mathrm{m}}\right)$ e $\mathrm{D}_{50}$ de, respectivamente, 5,64 $\mu \mathrm{m}$ e 4,29 $\mu \mathrm{m}$ para M2_A1_D, 7,40 $\mu \mathrm{m}$ e $5,82 \mu \mathrm{m}$ para M2_A1_R, 3,60 $\mu \mathrm{m}$ e 3,02 $\mu \mathrm{m}$ para M2 A1_P, $5,72 \mu \mathrm{m}$ e $4,35 \mu \mathrm{m}$ para M2_A3_D, 7,44 $\mu \mathrm{m}$ e $5,83 \mu \mathrm{m}$ para M2_A3_R, 3,80 $\mu \mathrm{m}$ e 3,18 $\mu \mathrm{m}$ para M2_A3_P. Ainda é possível observar que a porcentagem da massa acumulada que apresenta diâmetro médio equivalente abaixo de $2 \mu \mathrm{m}$, que corresponde à fração argila, é de $23,29 \%$ para M2 A1_D, $15,97 \%$ para M2_A1_R, 32,89\% para M2_A1_P, $22,98 \%$ para M2_A3_D, 15,83\% para M2_A3_R, 30,81\% para M2_A3_P.

As Figs. 8a e 8b mostram que todas as amostras apresentam curva de distribuição de partículas monomodal, exceto a amostra M3_A1_P, na qual, porém, ocorre a predominância da distribuição monomodal. As amostras apresentam diâmetros médio $\left(\mathrm{D}_{\mathrm{m}}\right)$ e $\mathrm{D}_{50}$ de, respectivamente, $5,75 \mu \mathrm{m}$ e $4,33 \mu \mathrm{m}$ para M3_A1_D, 7,63 $\mu \mathrm{m}$ e 5,99 $\mu \mathrm{m}$ para M3_A1_R, 3,52 $\mu \mathrm{m}$ e $3,01 \mu \mathrm{m}$ para M3_A1_P, 5,90 $\mu \mathrm{m}$
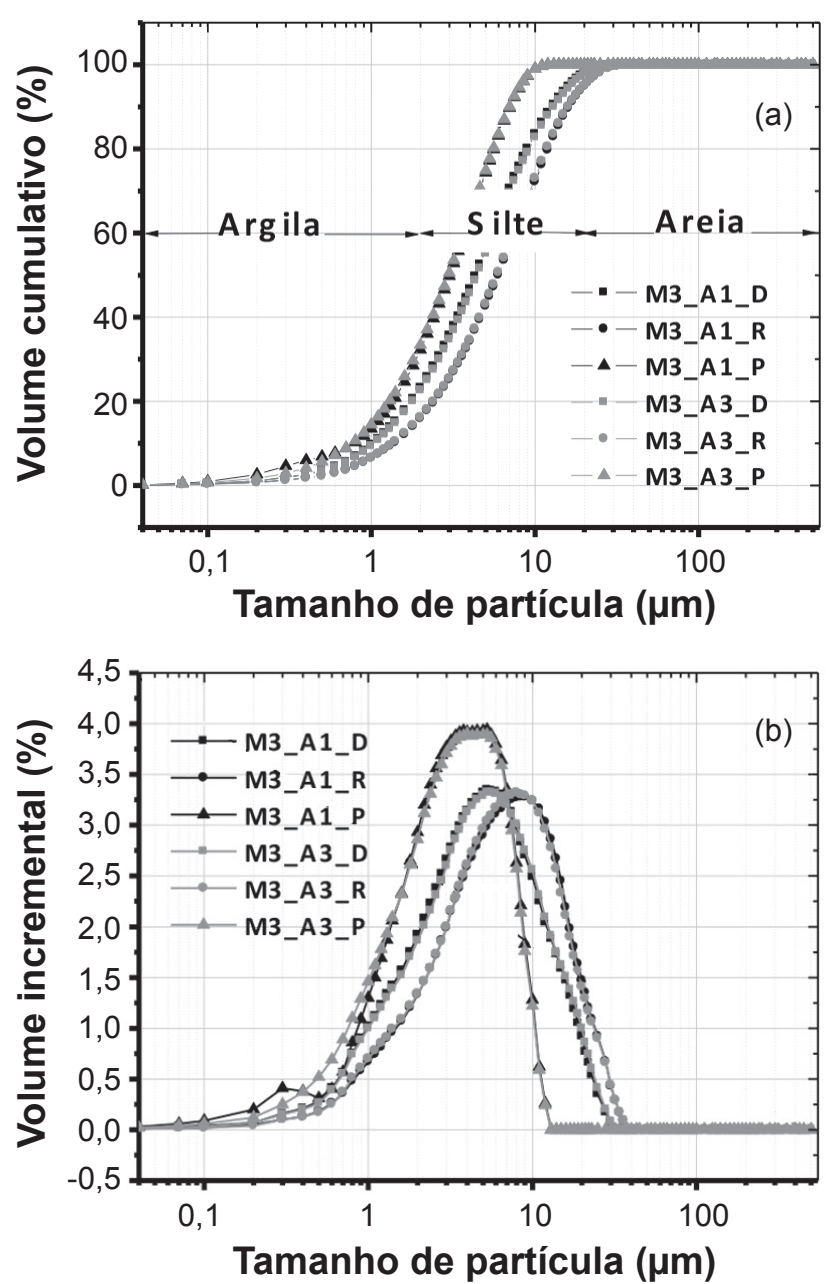

Figura 8: Curvas de granulometria da mistura M3 nas configurações A1 e A3 do hidrociclone. (a) volume acumulado passante e (b) distribuição do tamanho de partículas.

[Figure 8: Particle size of the mixture M3 in the configurations A1 and $A 3$ of the hydrocyclone. (a) cumulative volume passing and (b) particle size distribution.]

e 4,43 $\mu \mathrm{m}$ para M3_A3_D, 7,54 $\mu \mathrm{m}$ e $5,91 \mu \mathrm{m}$ para M3 A3_R, 3,48 $\mu \mathrm{m}$ e $2,97 \mu \mathrm{m}$ para M3_A3_P. Ainda é possível observar que a porcentagem da massa acumulada que apresenta diâmetro médio equivalente abaixo de $2 \mu \mathrm{m}$, que corresponde à fração argila, é de 23,23\% para M3_A1_D, $15,90 \%$ para M3_A1_R, 32,27\% para M3_A1_P, $22,60 \%$ para M3 A3 D, $16,15 \%$ para M3 A3 R e $3 \overline{3}, 41 \%$ para M3 A3 P.

Assim, verifica-se através da análise granulométrica que a operação de hidrociclonagem resulta em concentrados de argilominerais com menores diâmetros médios e rejeitos com maiores diâmetros médios em relação à dispersão original, evidenciando que tal operação é capaz de promover separação granulométrica e consequente eliminação de contaminantes. Há ainda um significativo aumento de fração argila em todos os concentrados com relação às dispersões antes da hidrociclonagem, o que nos leva a concluir que a operação de hidrociclonagem é eficiente no que propõe quando da utilização das configurações A1 ou A3. 
Difração de raios $X(D R X)$ das amostras hidrociclonadas

Nas Figs. 9 a 14 são apresentadas as ampliações dos principais picos de montmorilonita e quartzo das amostras M1, M2 e M3 hidrociclonadas nas configurações A1 e A3 do hidrociclone e suas respectivas dispersões originais. Na Fig. 9a são apresentadas as ampliações dos principais picos de montmorilonita da dispersão original $(14,41 \AA$ $(2 \theta=6,13))$, do concentrado de argilominerais $(14,88 \AA$ $(2 \theta=5,94))$ e do rejeito $(15,60 \AA(2 \theta=5,66)$ da mistura M1 hidrociclonada na configuração A1. Na Fig. 9b são apresentadas as ampliações dos principais picos de quartzo da dispersão original $(3,33 \AA(2 \theta=26,75))$, do concentrado de argilominerais $(3,32 \AA(2 \theta=26,81))$ e do rejeito $(3,35 \AA$ ( $2 \theta$ $=26,61)$ ) da mistura M1 hidrociclonada na configuração A1. $\mathrm{O}$ rejeito apresenta o pico característico da montmorilonita em intensidade ligeiramente maior que da dispersão original
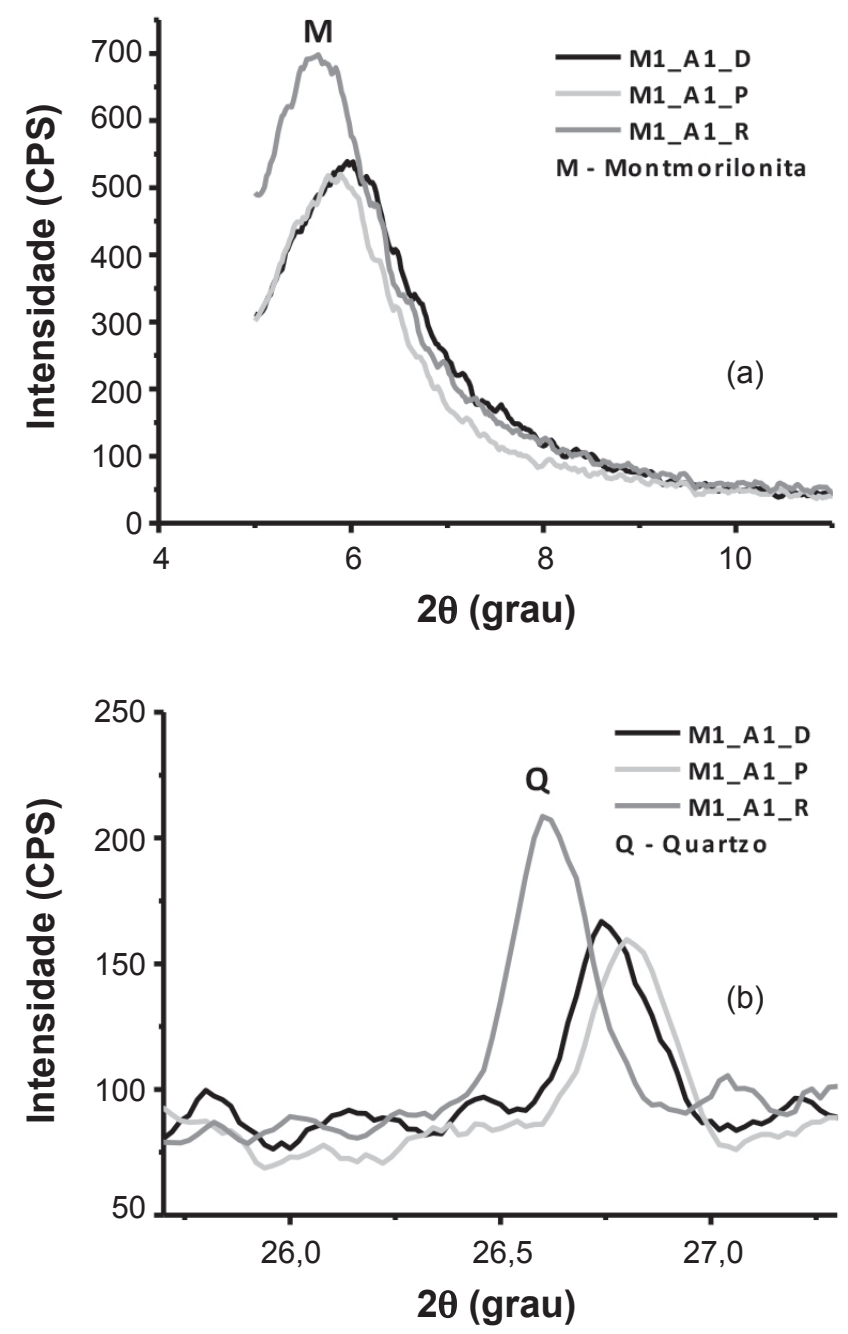

Figura 9: Ampliação do principal pico de difração de raios $X$ da montmorilonita (a) e do quartzo (b) da mistura M1 na configuração A1 do hidrociclone.

[Figure 9: Magnification of the main X-ray diffraction peak of montmorillonite (a) and of the quartz (b) of the mixture MI in the configuration Al of the hydrocyclone.] e do concentrado de argilominerais, indicando perda de fração argila no rejeito, provavelmente na forma de aglomerados. Verifica-se também aumento da intensidade do pico característico do quartzo no rejeito e diminuição no concentrado de argilominerais, evidenciando que mesmo com perda de fração argila no rejeito, algo indesejado, ocorre redução da intensidade da fração acessória na forma de quartzo, o que favorece a reologia [17].

$\mathrm{Na}$ Fig. 10a são apresentadas as ampliações dos principais picos de montmorilonita da dispersão original $(15,39 \AA(2 \theta=5,74))$, do concentrado de argilominerais $(16,01 \AA(2 \theta=5,52))$ e do rejeito $(15,95 \AA(2 \theta=5,54))$ da mistura M1 hidrociclonada na configuração A3. Na Fig. 10b são apresentadas as ampliações dos principais picos de quartzo da dispersão original $(3,34 \AA(2 \theta=26,67))$, do concentrado de argilominerais $(3,36 \AA(2 \theta=26,54))$ e do rejeito $(3,35 \AA(2 \theta=26,61))$ da mistura M1 hidrociclonada
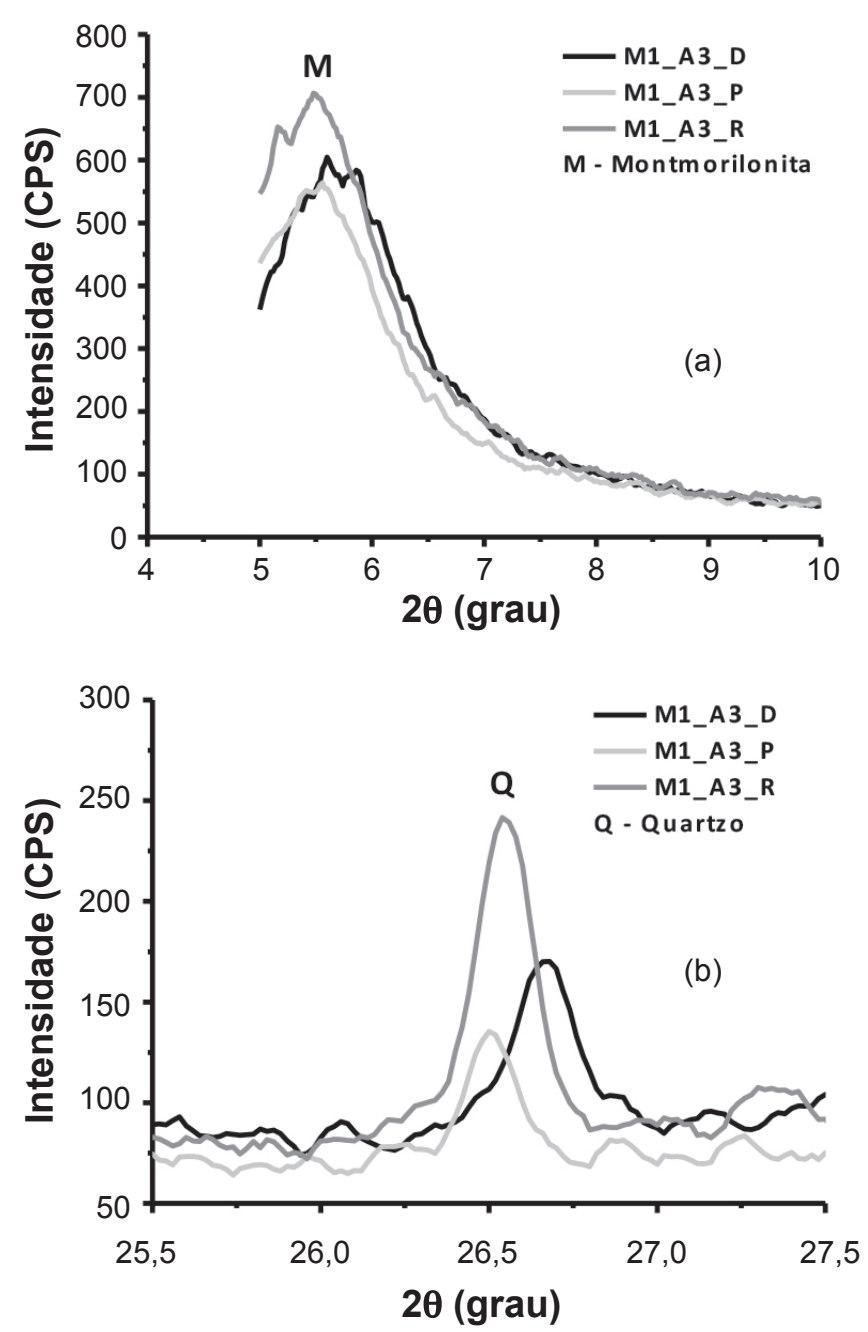

Figura 10: Ampliação do principal pico de difração de raios X de montmorilonita (a) e do quartzo (b) da mistura M1 na configuração A3 do hidrociclone.

[Figure 10: Magnification of the main X-ray diffraction peak of montmorillonite (a) and of the quartz (b) of the mixture M1 in the configuration A3 of the hydrocyclone.] 

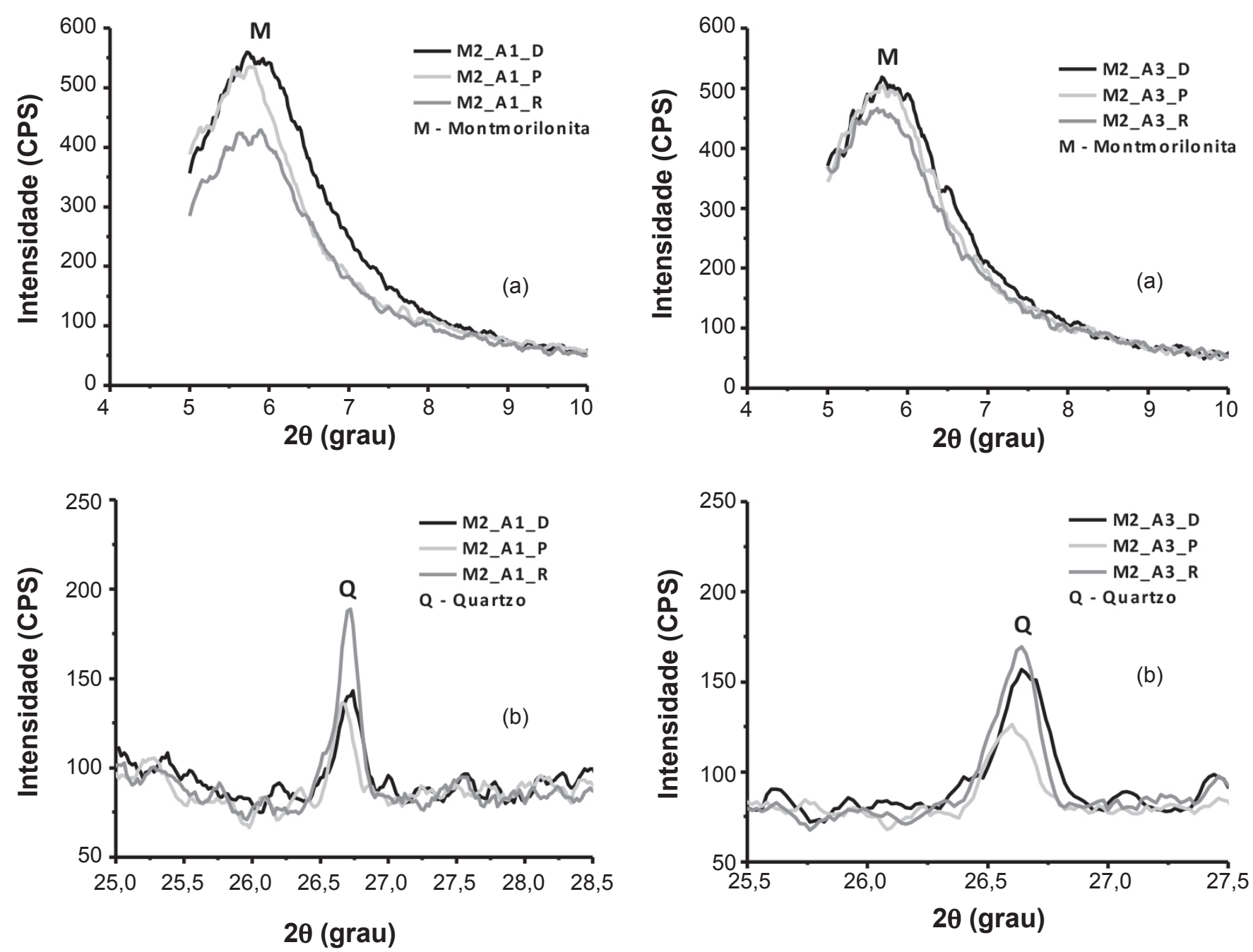

Figura 11: Ampliação do principal pico difração de raios $\mathrm{X}$ de montmorilonita (a) e do quartzo (b) da mistura M2 na configuração A1 do hidrociclone.

[Figure 11: Magnification of the main X-ray diffraction peak of montmorillonite (a) and of the quartz (b) of the mixture M2 in the configuration Al of the hydrocyclone.]

na configuração A3. É possível observar que o rejeito apresenta o pico característico da montmorilonita em intensidade ligeiramente maior que da dispersão original e do concentrado de argilominerais. Verifica-se também significativo aumento da intensidade do pico característico do quartzo no rejeito e diminuição no concentrado de argilominerais, evidenciando o mesmo comportamento da mistura M1 na configuração A1.

Na Fig. 11a são apresentadas as ampliações dos principais picos de montmorilonita da dispersão original $(14,60 \AA$ $(2 \theta=6,06))$, do concentrado de argilominerais $(15,36 \AA$ $(2 \theta=5,75))$ e do rejeito $(14,77 \AA(2 \theta=5,98))$ da mistura M2 hidrociclonada na configuração A1. Na Fig. 11b são apresentadas as ampliações dos principais picos de quartzo da dispersão original $(3,33 \AA(2 \theta=26,75))$, do concentrado de argilominerais $(3,34 \AA(2 \theta=26,67))$ e do rejeito $(3,33 \AA$ $(2 \theta=26,75))$ da mistura M2 hidrociclonada na configuração

Figura 12: Ampliação do principal pico de difração de raios X de montmorilonita (a) e do quartzo (b) da mistura M2 na configuração A3 do hidrociclone.

[Figure 12: Magnification of the main X-ray diffraction peak of montmorillonite (a) and of the quartz (b) of the mixture M2 in the configuration A3 of the hydrocyclone.]

A1 do hidrociclone. O concentrado de argilominerais apresenta o pico característico da montmorilonita na mesma intensidade do pico da dispersão original. Verifica-se também aumento da intensidade do pico característico do quartzo no rejeito e diminuição no concentrado de argilominerais, evidenciando a redução da fração acessória na forma de quartzo, o que, como já dissemos, favorece a reologia [17].

Na Fig. 12a são apresentadas as ampliações dos principais picos de montmorilonita da dispersão original $(14,46 \AA$ $(2 \theta=6,11))$, do concentrado de argilominerais $(15,36 \AA$ $(2 \theta=5,75))$ e do rejeito $16,00 \AA(2 \theta=5,52)$ da mistura M2 hidrociclonada na configuração A3. Na Fig. 12b são apresentadas as ampliações dos principais picos de quartzo da dispersão original $(3,34 \AA(2 \theta=26,67))$, do concentrado de argilominerais $(3,34 \AA(2 \theta=26,67))$ e do rejeito $(3,35 \AA$ $(2 \theta=26,61))$ da mistura M2 hidrociclonada na configuração A3 do hidrociclone. O concentrado de argilominerais 

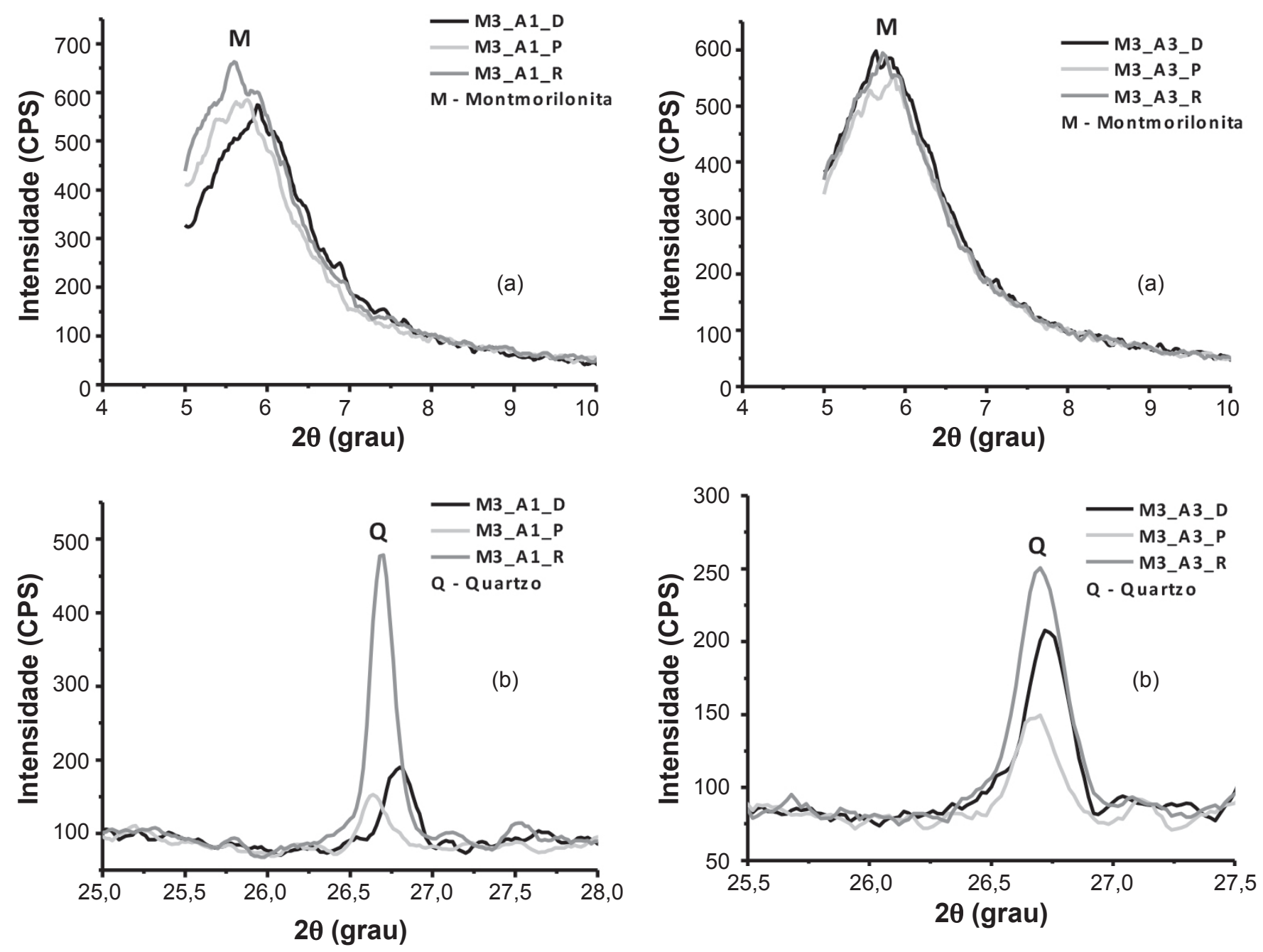

Figura 13: Ampliação do principal pico de difração de raios $X$ de montmorilonita (a) e do quartzo (b) da mistura M3 na configuração A1 do hidrociclone.

[Figure 13: Magnification of the main X-ray diffraction peak of montmorillonite (a) and of the quartz (b) of the mixture M3 in the configuration Al of the hydrocyclone.]

apresenta o pico característico da montmorilonita na mesma intensidade do pico da dispersão original. Verificase também que ocorre aumento da intensidade do pico característico do quartzo no rejeito e diminuição no concentrado de argilominerais, evidenciando novamente a redução da fração acessória na forma de quartzo, o que favorece a reologia [17].

$\mathrm{Na}$ Fig. 13a são apresentadas as ampliações dos principais picos de montmorilonita da dispersão original $(14,86 \AA(2 \theta=5,95))$, do concentrado de argilominerais $(15,41 \AA(2 \theta=5,73))$ e do rejeito $(15,85 \AA(2 \theta=5,58))$ da mistura M3 hidrociclonada na configuração A1 do hidrociclone. Na Fig. 13b são apresentadas as ampliações dos principais picos de quartzo da dispersão original $(3,32 \AA(2 \theta=26,80))$, do concentrado de argilominerais $(3,35 \AA(2 \theta=26,61))$ e do rejeito $(3,34 \AA(2 \theta=26,67))$ da mistura M3 hidrociclonada na configuração A1. O

Figura 14: Ampliação do principal pico de difração de raios X de montmorilonita (a) e do quartzo (b) da mistura M3 na configuração A3 do hidrociclone.

[Figure 14: Magnification of the main X-ray diffraction peak of montmorillonite (a) and of the quartz (b) of the mixture M3 in the configuration A3 of the hydrocyclone.]

rejeito apresenta o pico característico da montmorilonita em intensidade ligeiramente maior que da dispersão original e do concentrado de argilominerais, indicando perda de fração argila no rejeito, provavelmente também na forma de aglomerados. Há ainda significativo aumento da intensidade do pico característico do quartzo no rejeito e diminuição no concentrado de argilominerais, evidenciando o mesmo comportamento visto ate então.

$\mathrm{Na}$ Fig. 14a são apresentadas as ampliações dos principais picos de montmorilonita da dispersão original $(15,45 \AA(2 \theta=5,72))$, do concentrado de argilominerais $(15,10 \AA(2 \theta=5,86))$ e do rejeito $(15,22 \AA(2 \theta=5,81))$ da mistura M3 hidrociclonada na configuração A3. Na Fig. $14 \mathrm{~b}$ são apresentadas as ampliações dos principais picos de quartzo da dispersão original $(3,33 \AA(2 \theta=26,75))$, do concentrado de argilominerais $(3,34 \AA(2 \theta=26,67))$ e do rejeito $(3,34 \AA(2 \theta=26,67))$ da mistura M3 hidrociclonada 
na configuração A3 do hidrociclone. O concentrado de argilominerais e o rejeito apresentam o pico característico da montmorilonita na mesma intensidade do pico da dispersão original. Há também significativo aumento da intensidade do pico característico do quartzo no rejeito e diminuição no concentrado de argilominerais, evidenciando redução da fração acessória na forma de quartzo, o que favorece a reologia [17], e indica a eficiência da operação de hidrociclonagem na remoção do acessório.

Como visto, as amostras M1_A1_R, M1_A3_R e M3_A1_R apresentam aumento da intensidade do pico característico da montmorilonita, o que não é desejado, entretanto ocorre aumento da intensidade do pico característico de quartzo em todas as amostras de rejeito e diminuição nas amostras de concentrado de argilominerais, o que favorece a reologia, mesmo com a perda da fração argila. O quartzo não possui qualquer interação com a água e em uma suspensão sua presença reduz a fração argila. Sua presença em finas granulometrias permite uma competição com os sítios $\mathrm{Na}^{+}$na superfície da argila, tornando a estrutura similar a das bentonitas com cátion predominante de $\mathrm{Ca}^{2+}$ [17]. Destacamos também que a perda de aglomerados de argila no rejeito, é pouco influente, visto que as melhores propriedades advêm das partículas finas de argila, ainda presentes em grande quantidade no concentrado.

Análise granulométrica por difração a laser dos concentrados de argilominerais obtidos por hidrociclonagem e secos por spray dryer

A seguir são apresentados os resultados de AG realizadas nos concentrados de argilominerais das misturas M1, M2 e M3 obtidos por hidrociclonagem e secos por spray dryer. Nas Figs 15a e 15b todas as amostras apresentam curva de distribuição de partículas monomodal, exceto as amostras M1_A1_P_50, M3_A1_P_35 e M3_A1_P_50, nas quais, porém, ocorre a predominância da distribuiçãa monomodal. Os diâmetros médio $\left(\mathrm{D}_{\mathrm{m}}\right)$ e $\mathrm{D}_{50}$ são, respectivamente, 6,01 $\mu \mathrm{m}$ e 5,23 $\mu \mathrm{m}$ para M1_A1_P_35, 4,99 $\mu \mathrm{m}$ e 4,69 $\mu \mathrm{m}$ para M1_A1_P_50, 5,98 $\mu \mathrm{m}$ e $5,37 \mu \mathrm{m}$ para M2_A1_P_35, $5,38 \mu \mathrm{m}$ e $4,78 \mu \mathrm{m}$ para M2_A1_P_50, 5,59 $\mu \mathrm{m}$ e 5,28 $\mu \mathrm{m}$ para M3_A1_P_35, 5,24 $\mu \mathrm{m}$ e $4, \overline{8} 7 \mu \mathrm{m}$ para M3_A1_P_50. Ainda é possível observar que a porcentagem da massa acumulada que apresenta diâmetro médio equivalente abaixo de $2 \mu \mathrm{m}$, que corresponde à fração argila, é de 8,59\% para M1_A1_P_35, 10,00\% para M1_A1_P_50, $8,60 \%$ para M2 A1_P $35,8,86 \%$ para M2 A1 P 50 , 9,27\% para M3_A1_P_35, 8,75\% para M3_A1_P_50.

Nas Figs. 16a e 16b as amostras M2_A3_P_35 e M3 A3_P_35 apresentam curva de distribuição de partículas monomodal, nas demais, porém, ocorre a predominância da distribuição monomodal. Ainda é possível inferir que os diâmetros médio $\left(\mathrm{D}_{\mathrm{m}}\right)$ e $\mathrm{D}_{50}$ são, respectivamente, 5,44 $\mu \mathrm{m}$ e 5,16 $\mu \mathrm{m}$ para M1_A3_P_35, 5,15 $\mu \mathrm{m}$ e 4,77 $\mu \mathrm{m}$ para M1_A3_P_50, 5,86 $\mu \mathrm{m}$ e 5,27 $\mu \mathrm{m}$ para M2_A3_P_35, $4,99 \mu \mathrm{m}$ e $4,72 \mu \mathrm{m}$ para M2_A3_P_50, 5,62 $\mu \mathrm{m}$ e 5,27 $\mu \mathrm{m}$ para M3_A3_P_35, $5,16 \mu \mathrm{m}$ e $4, \overline{7} 1 \mu \mathrm{m}$ para M3_A3_P_50.
Ainda é possível observar que a porcentagem da massa acumulada que apresenta diâmetro médio equivalente abaixo de $2 \mu \mathrm{m}$, que corresponde à fração argila, é de $8,90 \%$ para M1_A3_P_35, 8,82\% para M1_A3_P_50, 8,67\% para M2_A3_P_35, 9,60\% para M2_A3_P_50, 8,13\% para M3_A3_P_35, 9,10\% para M3_A3_P_50.

A secagem por spray dryer proporciona aglomerados de menor diâmetro médio de acordo com o aumento da vazão de ar comprimido, ou seja, as amostras secas a $35 \mathrm{~L} / \mathrm{min}$ de ar comprimido têm maior diâmetro médio de aglomerados que as amostras secas a $50 \mathrm{~L} / \mathrm{min}$. Tal fato deve-se a maior fragmentação da corrente líquida em gotículas provocada pelo aumento da vazão de ar [13], ou seja, uma vez que aumenta-se a vazão de ar, a corrente líquida passa por uma maior nebulização, formando um maior número de gotas e de menor tamanho.
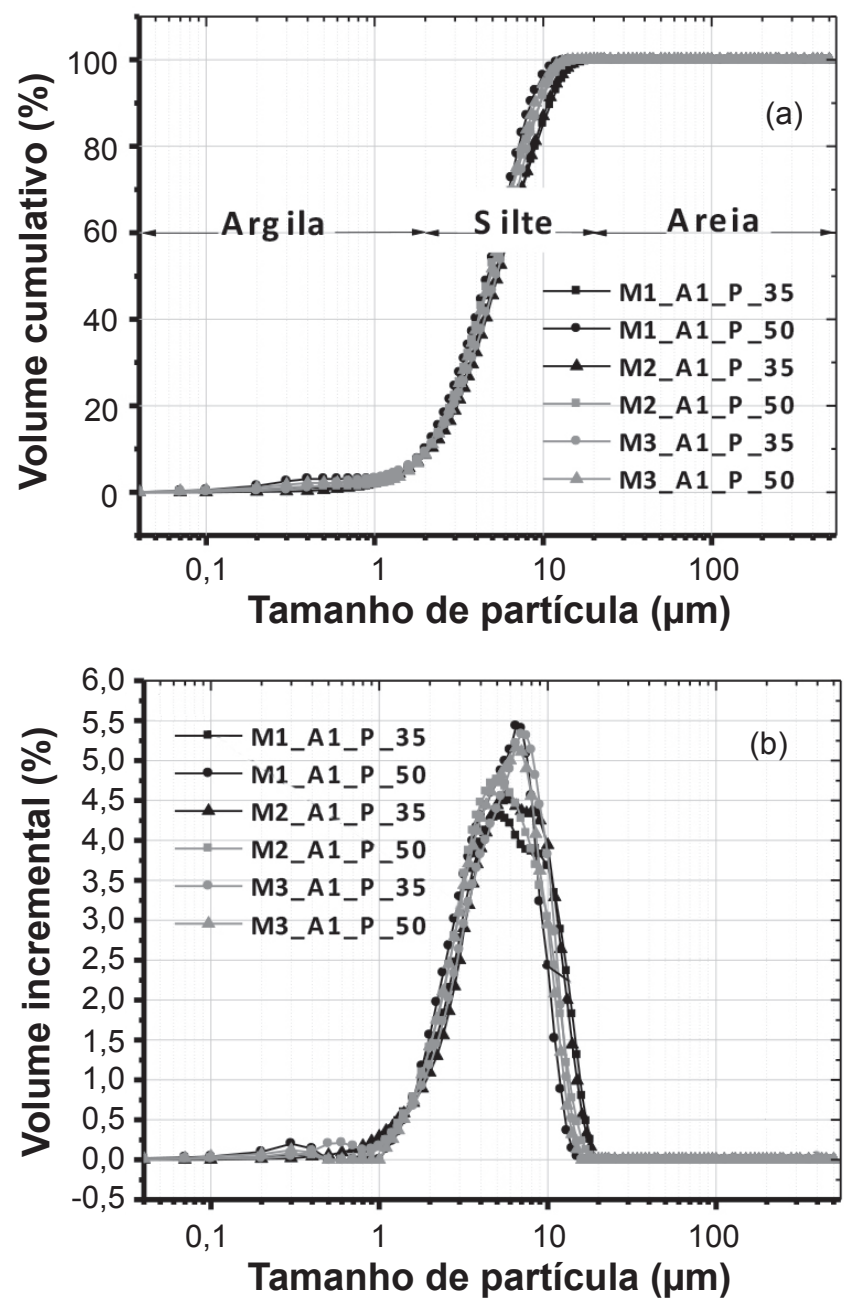

Figura 15: Curvas de granulometria dos concentrados de argilominerais das misturas M1, M2 e M3 na configuração A1 do hidrociclone com secagem por spray dryer. (a) volume acumulado passante e (b) distribuição do tamanho de partículas.

[Figure 15: Particle size of the concentrates of clay minerals of the mixtures M1, M2 and M3 in the configuration A1 of the hydrocyclone with drying by spray dryer. (a) cumulative volume passing and (b) particle size distribution.] 

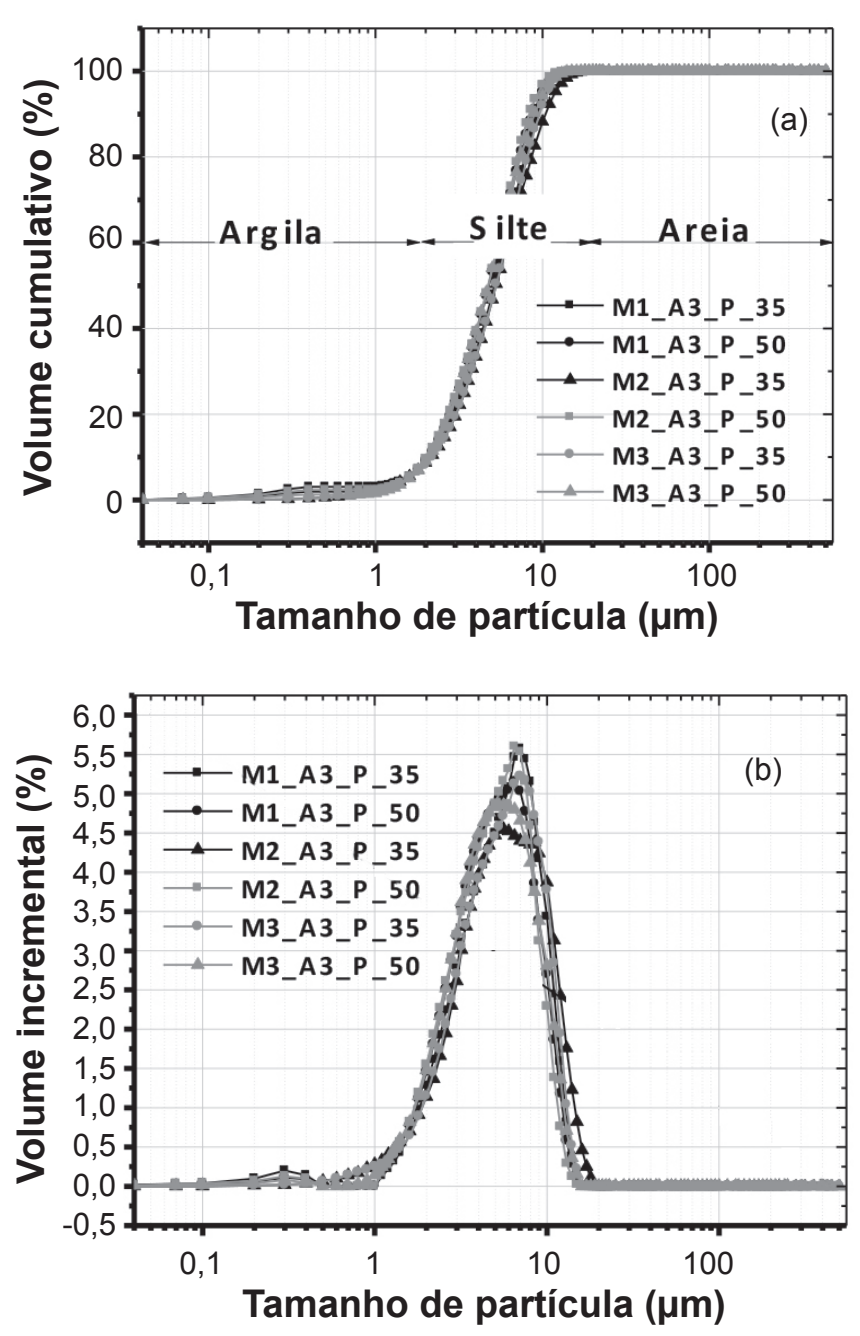

Figura 16: Curvas de granulometria dos concentrados de argilominerais das misturas M1, M2 e M3 na configuração A3 do hidrociclone com secagem por spray dryer. (a) volume acumulado passante e (b) distribuição do tamanho de partículas.

[Figure 16: Particle size of the concentrates of clay minerals of the mixtures M1, M2 and M3 in the configuration A3 of the hydrocyclone with drying by spray dryer. (a) cumulative volume passing and (b) particle size distribution.]

\section{Estudo reológico com os concentrados de argilominerais}

Nas figuras a seguir são apresentados os resultados de reologia para as amostras sem passar pela operação de hidrociclonagem e para os concentrados de argilominerais secos por spray dryer. As Figs. 17a e 17b referem-se às viscosidades dos concentrados de argilominerais obtidos pelas configurações A1 e A3, respectivamente. Analisando as figuras é possível observar uma melhoria significativa de VA para todas as misturas após a hidrociclonagem nas configurações A1 e A3 do hidrociclone com secagem por spray dryer. Já na VP, a melhoria mais expressiva ocorreu para a mistura M2 em ambas as configurações do hidrociclone com secagem por spray dryer.

A Fig. 18 refere-se aos volumes de filtrado das amostras sem passar por hidrociclonagem e dos concentrados de
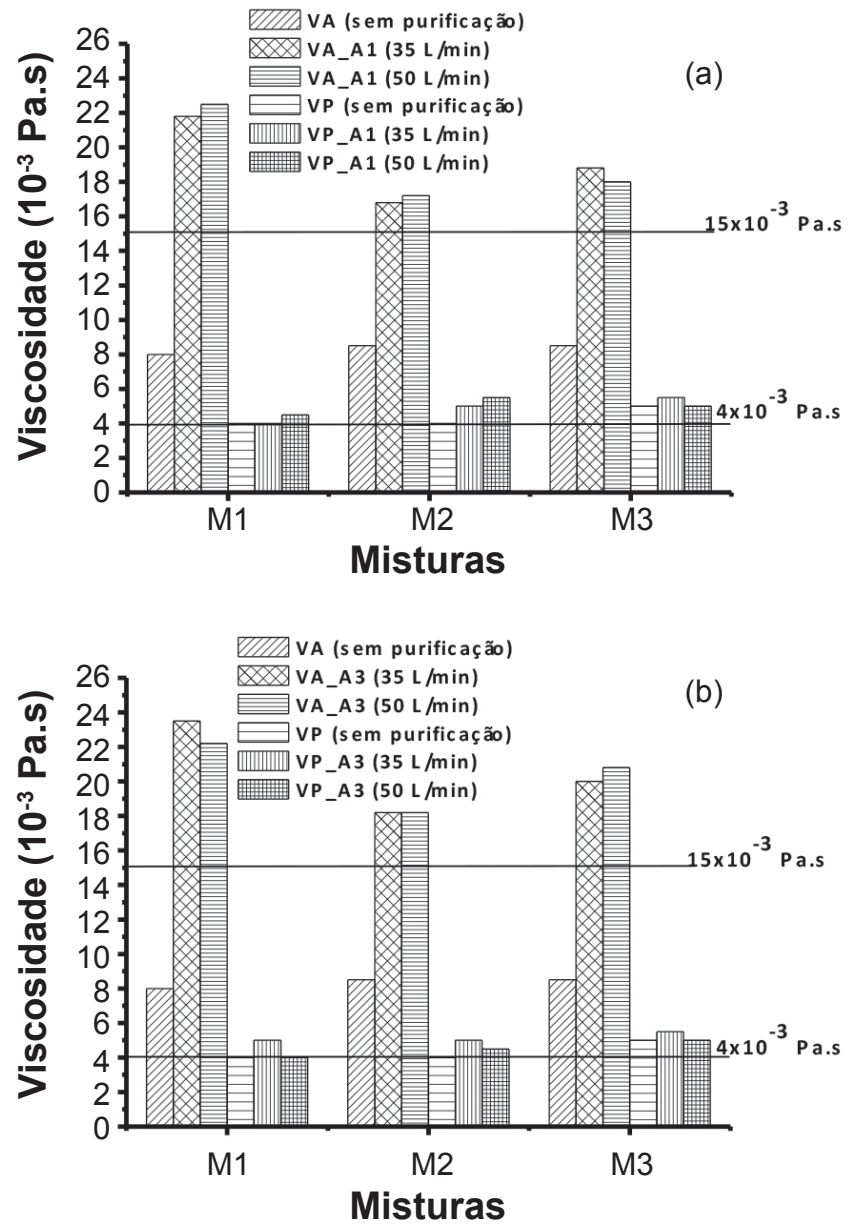

Figura 17: Viscosidade Aparente (VA) e Viscosidade Plástica (VP) das amostras M1, M2 e M3 sem hidrociclonagem e hidrociclonadas nas configurações (a) A1 e (b) A3 do hidrociclone.

[Figure 17: Apparent viscosity (AV) and plastic viscosity (PV) of the samples M1, M2 and M3 without hydrocycloning and hydrocycloning in the configurations (a) A1 and (b) A3 of the hydrocyclone.]

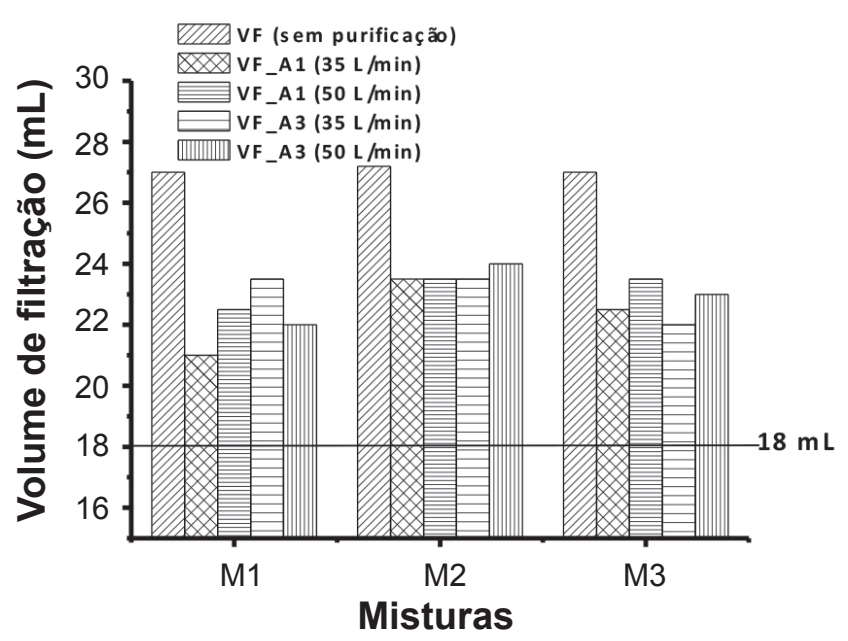

Figura 18: VF das amostras M1, M2 e M3 sem hidrociclonagem e hidrociclonadas nas configurações A1 e A3 do hidrociclone.

[Figure 18: Filtrate volume (FV) of the samples M1, M2 and M3 without hydrocycloning and hydrocycloning in the configurations Al and $A 3$ of the hydrocyclone.] 
argilominerais obtidos pelas configurações A1 e A3. É possível observar melhoria de VF para todas as misturas hidrociclonadas em ambas as configurações do hidrociclone. No entanto, a maior redução ocorreu para a mistura M1 hidrociclonada na configuração A1 e seca por spray dryer a $35 \mathrm{~L} / \mathrm{min}$ de ar comprimido.

As melhorias para as propriedades reológicas das misturas devem-se, provavelmente, além, da operação de hidrociclonagem, ao modo de secagem, uma vez que o aquecimento e a transferência de massa durante a secagem por spray dryer ocorrem com filmes de ar e vapor ao redor das gotículas. Esta proteção do vapor mantém a partícula na temperatura de saturação. Como a partícula não se torna seca, a evaporação continua acontecendo e a temperatura dos sólidos não se aproxima da temperatura de saída da secagem. Assim, produtos sensíveis podem ser secos em temperaturas relativamente altas [14]. Outra vantagem da secagem por spray dryer é a curta exposição dos produtos aos gases quentes, ao mesmo tempo em que a evaporação do líquido das gotículas mantém a temperatura do produto baixa [13]. Tais fatos diminuem a possibilidade de contração das camadas do argilomineral [18], o que dificultaria a posterior hidratação, logo o comportamento reológico das dispersões também seria afetado. Assim, a secagem por spray dryer é extremamente vantajosa, uma vez que não permite a secagem excessiva de argilas bentoníticas mantendo os teores de umidade ainda dentro da normatização da Petrobras [5]. A melhoria nas propriedades de pós secos por pulverização também foi verificada quando da secagem por spray dryer de argilas pilarizadas com Al, Al-Co, Al-Cu e Al-Co-Cu [19].

\section{CONCLUSÕES}

Do ponto de vista da análise granulométrica e difração de raios X, as configurações A1 e A3 do hidrociclone são capazes de promover separação por tamanho e densidade de partículas, de forma a concentrar argilominerais finos no overflow e minerais acessórios e aglomerados de argilominerais no underflow, não ocorrendo diferenças significativas quando da utilização das configurações A1 ou A3. Os ensaios reológicos revelaram melhoria significativa para VA, chegando a atingir o mínimo especificado pela EP1EP-00011-A da Petrobras, para todas as misturas após a operação de hidrociclonagem nas configurações A1 e A3 do hidrociclone com secagem por spray dryer. Já para o VF, há melhorias em todas as misturas em ambas as configurações do hidrociclone, porém não o suficiente para obedecer a referida especificação. Quanto a secagem por spray dryer, verifica-se que, do ponto de vista da análise granulométrica, a secagem a $50 \mathrm{~L} / \mathrm{min}$ de ar comprimido é a mais adequada, uma vez que proporciona aglomerados com menores diâmetros médios. Já do ponto de vista das propriedades reológicas, tanto a secagem a $35 \mathrm{~L} / \mathrm{min}$ quanto a secagem a $50 \mathrm{~L} / \mathrm{min}$ proporcionam valores de viscosidade acima dos exigidos pela norma. Portanto, conclui-se que é possível a obtenção de dispersões hidroargilosas com propriedades reológicas que atendam as exigências normativas vigentes a partir de argilas pouco nobres. No entanto, fazem-se necessários estudos quanto ao seu volume de filtrado.

\section{REFERÊNCIAS}

[1] H. S. Ferreira, R. R. Menezes, H. S. Ferreira, A. B. Martins, G. A. Neves, H. C. Ferreira, Cerâmica 54 (2008) 77-85.

[2] P. Souza Santos, Ciência e Tecnologia de Argilas, $2^{\mathrm{a}}$ Ed., Vol. 1, Edgard Blücher, S. Paulo, SP (1989).

[3] A. B. Luz, J. A. Sampaio, M. A. A. Neto, Com. Tec., Usina de Beneficiamento de Minérios do Brasil, CT2002188-00 Bentonita, União Brasileira de Mineração, Rio de Janeiro (12/2002), disponível em <http://www.cetem.gov. br/ publicacao/CTs/CT2002-188-00.pdf >, aAcesso em 17/10/2014.

[4] A. R. V. Silva, H. C. Ferreira, Rev. Eletr. Mater. Proc. 3.2 (2008) 26-35.

[5] Petrobras, "Viscosificante para fluidos usados na exploração e produção de poços de petróleo e gás", Padrão Código: EP-1EP-00011-A, 11/08/2011, 14 p.

[6] L. V. Amorim, E. Pereira, C. M. Gomes, J. D. Viana, K. V. Farias, M. I. R. Barbosa, K. B. França, H. L. Lira, H. C. Ferreira, Rev. Águas Subterrâneas 18 (2004) 9-17.

[7] R. R. Menezes, P. M. Souto, L. N. L. Santana, G. A. Neves, R. H. G. A. Kiminami, H. C. Ferreira, Cerâmica 55 (2009) 163-169.

[8] F. Boylu, K. Çinku, F. Esenli, M. S. Çelik, Int. J. Mineral Proc. 94 (2010) 196-202.

[9] J. M. R. Costa, I. A. Silva, H. S. Ferreira, R. R. Menezes, G. A. Neves, H. C. Ferreira, Cerâmica 58 (2012) 419-435.

[10] F. J. Souza, L. G. M. Vieira, J. J. R. Damasceno, M. A. S. Barrozo, Powder Technology 107 (2000) 259-267.

[11] E. A. Barbosa, L. G. M. Vieira, C. A. K. Almeida, J. J. R. Damasceno, M. A. S. Barrozo, Mater. Sci. Forum 416 (2003) 317-322.

[12] T. Kajiyama, K. J. Park, Rev. Bras. Prod. Agroind. 10, 1 (2008) 1-8.

[13] A. S. Foust, L. A. Wenzel, C. W. Clump, L. Maus, L. B. Andersen, Princípios das Operações Unitárias, $2^{\mathrm{a}}$ Ed., LTC, Rio de Janeiro, RJ (1982).

[14] S. C. da S. Lannes, M. L. Medeiros, Rev. Bras. Ci. Farmac. 39, 1 (2003) 115-123.

[15] V. C. Marques, I. B. C. Dias, J. B. Alves, L. F. A. Campos, R. P. S. Dutra, H. S. Ferreira, Mater. Sci. Forum 798-799 (2014) 27-32.

[16] H. S. Ferreira, L. F. A. Campos, R. R. Menezes, J. M. Cartaxo, L. N. L. Santana, G. A. Neves, H. C. Ferreira, Cerâmica 59 (2013) 277-284.

[17] M. Holmboe, S. Wold, T. Petterson, Phys. Chem. Earth 36 (2011) 1580-1589.

[18] P. Souza Santos. Ciência e Tecnologia de Argilas, $2^{\mathrm{a}}$ Ed., Vol. 2, Edgard Blücher, S. Paulo, SP (1992) 596.

[19] C. M. Urruchurto, J. G. Carriazo, C. Osorio, S. Moreno, R. A. Molina, Powder Technol. 239 (2013) 451-57.

(Rec. 06/11/2014, Rev. 09/12/2014, 12/03/2015, Ac. $01 / 05 / 2015)$ 